\title{
Suppression of the Intrinsic Apoptosis Pathway by Synaptic Activity
}

\author{
Frédéric Léveillé, ${ }^{1 \star}$ Sofia Papadia, ${ }^{1 \star}$ Michael Fricker, ${ }^{2 \star}$ Karen F. S. Bell, ${ }^{1}$ Francesc X. Soriano, ${ }^{1}$ Marc-André Martel, ${ }^{1}$ \\ Clare Puddifoot, ${ }^{1}$ Marlen Habel, ${ }^{3}$ David J. Wyllie, ${ }^{1}$ Chrysanthy Ikonomidou, ${ }^{3,4}$ Aviva M. Tolkovsky, ${ }^{2}$ \\ and Giles E. Hardingham ${ }^{1}$ \\ ${ }^{1}$ Centre for Integrative Physiology, University of Edinburgh, Edinburgh EH8 9XD, United Kingdom, ${ }^{2}$ Department of Biochemistry, University of Cambridge, \\ Cambridge CB2 1QW, United Kingdom, ${ }^{3}$ Department of Pediatric Neurology, Technical University Dresden, 01307 Dresden, Germany, and ${ }^{4}$ Department of \\ Neurology and Waisman Center, University of Wisconsin, Madison, Wisconsin 53705
}

Synaptic activity promotes resistance to diverse apoptotic insults, the mechanism behind which is incompletely understood. We show here that a coordinated downregulation of core components of the intrinsic apoptosis pathway by neuronal activity forms a key part of the underlying mechanism. Activity-dependent protection against apoptotic insults is associated with inhibition of cytochrome $c$ release in most but not all neurons, indicative of anti-apoptotic signaling both upstream and downstream of this step. We find that enhanced firing activity suppresses expression of the proapoptotic BH3-only member gene Puma in a NMDA receptor-dependent, p53-independent manner. Puma expression is sufficient to induce cytochrome $c$ loss and neuronal apoptosis. Puma deficiency protects neurons against apoptosis and also occludes the protective effect of synaptic activity, while blockade of physiological NMDA receptor activity in the developing mouse brain induces neuronal apoptosis that is preceded by upregulation of Puma. However, enhanced activity can also confer resistance to Puma-induced apoptosis, acting downstream of cytochrome $c$ release. This mechanism is mediated by transcriptional suppression of apoptosome components Apaf-1 and procaspase-9, and limiting caspase-9 activity, since overexpression of procaspase-9 accelerates the rate of apoptosis in active neurons back to control levels. Synaptic activity does not exert further significant anti-apoptotic effects downstream of caspase-9 activation, since an inducible form of caspase- 9 overrides the protective effect of synaptic activity, despite activity-induced transcriptional suppression of caspase-3. Thus, suppression of apoptotic gene expression may synergize with other activity-dependent events such as enhancement of antioxidant defenses to promote neuronal survival.

\section{Introduction}

The intrinsic apoptosis pathway mediates the caspase-dependent death of cells in response to intrinsic signals (Benn and Woolf, 2004; Meier and Vousden, 2007). This involves mitochondrial permeability transition (MPT) and release of apoptotic factors including cytochrome $c$ and Smac/Diablo, controlled by the balance of pro- and anti-apoptotic members of the bcl-2 superfamily (Youle and Strasser, 2008). Members of the BH3-only domain subfamily promote mitochondrial release of apoptotic factors by antagonizing anti-apoptotic members of the bcl-2 subfamily, and facilitating the action of proapoptotic members of the Bax subfamily. Released cytochrome $c$ binds to Apaf-1 (apoptosis

Received 0ct. 14, 2009; accepted Jan. 3, 2010.

This work was funded by the Wellcome Trust, a Royal Society University Research fellowship (G.H.), The European Molecular Biology Organization Young Investigator Programme (G.H.), Medical Research Scotland, Tenovus Scotland, The European Network of Neuroscience Institutes, and the Biotechnology and Biological Sciences Research Council (G.H., M.F.). We thank Bert Vogelstein, David Spencer, Thomas Look, Takeshi Ono, and Kristian Helin for plasmids and Ariad for AP20187. We thank Alan Clarke for providing heterozygous p53 founder mice and Andreas Villunger for heterozygous Puma founder mice. K.F.S.B. is a recipient of a Canadian Institutes of Health Research fellowship.

${ }^{*}$ F.L., S.P., and M.F. contributed equally to the study.

Correspondence should be addressed to Giles E. Hardingham, Centre for Integrative Physiology, University of Edinburgh, Edinburgh EH8 9XD, UK. E-mail: giles.hardingham@ed.ac.uk.

D0I:10.1523/JNEUROSCI.5115-09.2010

Copyright $\odot 2010$ the authors $\quad 0270-6474 / 10 / 302623-13 \$ 15.00 / 0$ protease activating factor), which oligomerizes and recruits procaspase-9, which then becomes activated, forming the apoptosome (Riedl and Salvesen, 2007). Caspase-9 then proteolytically activates downstream effector caspases such as caspase-3 and -7 .

In the developing nervous system, apoptosis is crucial for the elimination of unwanted or inappropriately connected neurons (Buss et al., 2006). However, pathological apoptosis can take place following trauma such as oxidative stress, hypoxia/ischemia, and genotoxin exposure. Induction of neuronal apoptosis can occur via upregulation of BH3-only genes such as Puma (Wong et al., 2005; Wyttenbach and Tolkovsky, 2006; Kieran et al., 2007; Steckley et al., 2007). In the mature nervous system, neurons are less vulnerable to apoptosis, but it can still take place following the aforementioned trauma. Apoptotic-like neuronal death or the activation of apoptotic biochemical cascades (e.g., caspases) are proposed to be associated with certain neurodegenerative diseases, such as Alzheimer's and Parkinson's diseases (Viswanath et al., 2001; Mattson, 2006; Ribe et al., 2008; Rohn and Head, 2009), where the trigger may be oxidative stress, excitotoxins, or endoplasmic reticulum (ER) stress (Culmsee and Landshamer, 2006; Halliwell, 2006).

Apoptosis is also a feature of acute injury, including in the ischemic penumbra (Ray, 2006) and the pericontusional zone following mechanical trauma (Miñambres et al., 2008; Ribe et al., 
2008). Given the relevance of apoptosis and mitochondrial integrity to the development and pathophysiology of the CNS, it is important to understand endogenous mechanisms that suppress apoptosis, as this may lead to therapeutic targets and an understanding of pathological processes.

Survival of many neuronal types relies on physiological electrical activity, as evidenced by the deleterious effects of blocking activity in vivo and in vitro (Catsicas et al., 1992; Linden, 1994; Mennerick and Zorumski, 2000). Activity-dependent intracellular $\mathrm{Ca}^{2+}$ transients are important mediators of this neuroprotection, and the NMDA subtype of ionotropic glutamate receptors (NMDARs) is a key source of such transients. While high levels of NMDAR activity can be harmful, so too is blockade of normal synaptic NMDAR activity (Hardingham, 2009), indicating a prosurvival role for synaptic NMDARs. Neurons are particularly vulnerable to NMDAR blockade-induced apoptosis during postnatal development (Ikonomidou et al., 1999; Olney et al., 2002). However, in the adult rat brain NMDAR antagonists can also trigger neurodegeneration and exacerbate apoptosis induced by an additional trauma (Olney et al., 1989; Horváth et al., 1997; Wozniak et al., 1998; Ikonomidou et al., 2000) and prevent survival of newborn neurons in the adult dentate gyrus (Tashiro et al., 2006).

The exact molecular events that underlie the anti-apoptotic effect of synaptic activity are incompletely understood. We recently found that synaptic NMDAR activity boosts neuronal antioxidant defenses via a coordinated program of antioxidant gene transcription (Papadia et al., 2008). While changes in expression of these genes contribute to activity-dependent resistance to oxidative stress-induced apoptosis, they do not account for all of it. Synaptic activity can protect central neurons against a wide variety of apoptotic insults in vitro (Papadia et al., 2005). This raises the possibility that this protection is mediated by a common mechanism involving central components of the intrinsic apoptosis pathway. Here we show that synaptic activity promotes the transcriptional suppression of several key components of the core apoptotic machinery, promoting resistance to diverse apoptotic insults, including oxidative stress.

\section{Materials and Methods}

Neuronal cultures, stimulation, and the induction of apoptosis. Cortical mouse neurons were cultured as described previously (Papadia et al., 2008) at a density of between 9 and $13 \times 10^{4}$ neurons per $\mathrm{cm}^{2}$ from E17.5 mice with Neurobasal growth medium supplemented with B27 (Invitrogen). p53-null founder mice were obtained from Dr. Alan Clarke (University of Cardiff, Cardiff, UK) and were extensively crossed into the CD1 background. Puma-null founder mice were obtained from Dr. Andreas Strasser (The Walter and Eliza Hall Institute, Melbourne, VIC, Australia) (Villunger et al., 2003). Stimulations of cultured neurons were done in all cases after a culturing period of $8-10 \mathrm{~d}$ during which cortical neurons develop a network of processes, express functional NMDA-type and AMPA/kainate-type glutamate receptors, and form synaptic contacts. Our cultured neurons are 10-15\% GABAergic (assessed by immunofluorescence). Bursts of action potential firing were induced by treatment of neurons with $50 \mu \mathrm{M}$ bicuculline, and burst frequency was enhanced by addition of $250 \mu \mathrm{M} 4$-aminopyridine (Hardingham et al., 2001). MK-801 (used at $10 \mu \mathrm{M}$ ) was from Tocris Bioscience, TTX (at $2 \mu \mathrm{M}$ ) and 4-aminopyridine from Calbiochem. Neurons were subjected to trophic deprivation by transferring them from growth medium to a medium containing 10\% MEM (Invitrogen), 90\% salt-glucose-glycine (SGG) medium ((Bading et al., 1993); SGG: $114 \mathrm{~mm} \mathrm{NaCl}, 0.219 \% \mathrm{NaHCO}_{3}$, $5.292 \mathrm{~mm} \mathrm{KCl}, 1 \mathrm{~mm} \mathrm{MgCl}$, 2 mM CaCl $2,10 \mathrm{~mm}$ HEPES, 1 mm glycine, 30 mu glucose, $0.5 \mathrm{~mm}$ sodium pyruvate, $0.1 \%$ Phenol Red; osmolarity 325 $\mathrm{mOsm} / \mathrm{L},($ Papadia et al., 2005)). For this model, apoptosis was analyzed after $72 \mathrm{~h}$. Neurons were fixed and subjected to DAPI staining and cell death quantified by counting (blind) the number of apoptotic nuclei as a percentage of the total. Approximately 1500 cells were counted per treatment, across 4 independent experiments (i.e., performed on separate cultures). Morphologically, neurons subjected to trophic deprivation show typical signs of apoptotic-like cell death (shrunken cell body and large round chromatin clumps). Furthermore, death was blocked by the pan-caspase inhibitor QVD-Oph $(50 \mu \mathrm{M})$ (Fig. 1A). Chemical inducers of apoptosis were used as follows: staurosporine (Calbiochem, $100 \mathrm{~nm}$ ), 9-cis-retinoic acid (Sigma, $5 \mu \mathrm{M}$ ), okadaic acid (Calbiochem, $2 \mathrm{~nm}$ ), and hydrogen peroxide (Sigma, $100 \mu \mathrm{M}$ ). Cell death in all cases was blocked by pretreatment with QVD-Oph $(50 \mu \mathrm{M})$ [Fig. $1 \mathrm{~A}$ and Papadia et al. (2008)]. These inducers were applied to neurons for $24 \mathrm{~h}$, after which the percentage of apoptotic neurons was analyzed as described above.

In vivo $M K-801$ administration. Animal experiments were performed in accordance with the guidelines of the University of Technology, Dresden, Germany. Six-day-old (P6) male CD1 mice (Charles River) received two (at 0 and $8 \mathrm{~h}$ ) consecutive intraperitoneal injections of saline vehicle or the noncompetitive NMDA receptor antagonist dizocilpine (MK-801, Tocris Bioscience) in a dose of $0.5 \mathrm{mg} / \mathrm{kg}$ per injection $(10$ $\mathrm{ml} / \mathrm{kg}$ ). Pups were exposed to MK-801 or vehicle for up to $12 \mathrm{~h}$ after the first dose. The cingulate, retrosplenial, frontal, and parietal cortices were rapidly collected, pooled, and snap-frozen in liquid nitrogen. Samples were kept at $-80^{\circ} \mathrm{C}$ until further processing. Total cellular RNA was isolated by acidic phenol/chloroform extraction (Peqlab).

Caspase assays and inhibition. Cortical neurons plated in a 24-well plate were incubated for $5 \mathrm{~min}$ in $150 \mu \mathrm{l}$ of PBS supplemented with Triton X-100 0.5\%. Lysates were further homogenized by pipetting. Fifty microliters of the lysates were transferred in a 96-well plate containing 50 $\mu l$ of either Caspase-Glo 3/7 or Caspase-Glo 9 reagents (Promega) previously equilibrated at room temperature. As described in the manufacturer's instructions, MG-132 was added in the Caspase-Glo 9 reagent to reduce nonspecific background activity. Measurements were performed on FLUOstar OPTIMA (BMG Labtech). Caspase activity was then normalized to protein concentration measured by bicinchoninic acid (BCA) assay (Pierce Biotechnology) and expressed in fold induction compared to the corresponding control. Where used, QVD-Oph (Merck Biosciences) was used at $50 \mu \mathrm{M}$.

Immunofluorescence and Western blotting. Immunofluorescence was performed as described previously (Mckenzie et al., 2005). Pictures were taken on a Leica AF6000 LX imaging system, with a DFC350 FX digital camera. Primary antibodies used: Cytochrome $c$ (1:500, PharMingen), Puma (1:500, Prosci), anti-Smac/DIABLO (9H10, 1:100, Alexis). Antibody binding was visualized using biotinylated secondary antibody/Cy3conjugated streptavidin, or a Cy2 anti-mouse antibody. Nuclei were counter-stained with DAPI. For Western blotting, total cell lysates were boiled at $100^{\circ} \mathrm{C}$ for $5 \mathrm{~min}$ in $1.5 \times$ sample buffer $(1.5 \mathrm{~m}$ Tris, $\mathrm{pH} 6.8$; glycerol $15 \%$; SDS $3 \%$; $\beta$-mercaptoethanol $7.5 \%$; bromophenol blue $0.0375 \%)$. Gel electrophoresis and Western blotting were performed using Xcell Surelock system (Invitrogen) using precast gradient gels (4$20 \%$ ) according to the manufacturer's instructions. The gels were blotted onto PVDF membranes, which were then blocked for $1 \mathrm{~h}$ at room temperature with $5 \%(\mathrm{w} / \mathrm{v})$ nonfat dried milk in TBS with $0.1 \%$ Tween 20. The membranes were then incubated at $4^{\circ} \mathrm{C}$ overnight with the primary antibodies diluted in blocking solution: Puma (1:500, Prosci), Procaspase-9 (1:1000, Cell Signaling Technology), Apaf-1 (1:500, 13F11, Alexis), $\beta$-tubulin (1:100,000, Sigma). For visualization of Western blots, HRP-based secondary antibodies were used followed by chemiluminescent detection on Kodak X-Omat film. Western blots were analyzed by digitally scanning the blots, followed by densitometric analysis (ImageJ). All analysis involved normalizing to a loading control $\beta$-tubulin.

$R N A$ isolation, $R T-P C R$, and $q P C R$. RNA was isolated using the Qiagen RNeasy isolation reagents (including the optional DNase treatment) following passage of the cells through a QiaShredder column. For qPCR, cDNA was synthesized from $1-3 \mu \mathrm{g}$ of RNA using the Stratascript QPCR cDNA Synthesis kit (Stratagene) according to the manufacturer's instructions. Briefly, the required amount of RNA (up to $3 \mu \mathrm{g}$ ) was diluted in RNase-free water (up to $7 \mu$ l final volume) and mixed on ice with $2 \times$ cDNA Synthesis master mix ( $10 \mu \mathrm{l})$, random primers: oligo-dT primers 3:1 (total $2 \mu \mathrm{l}-200 \mathrm{ng}$ ) and either $1 \mu \mathrm{l}$ of RT/RNase block enzyme 

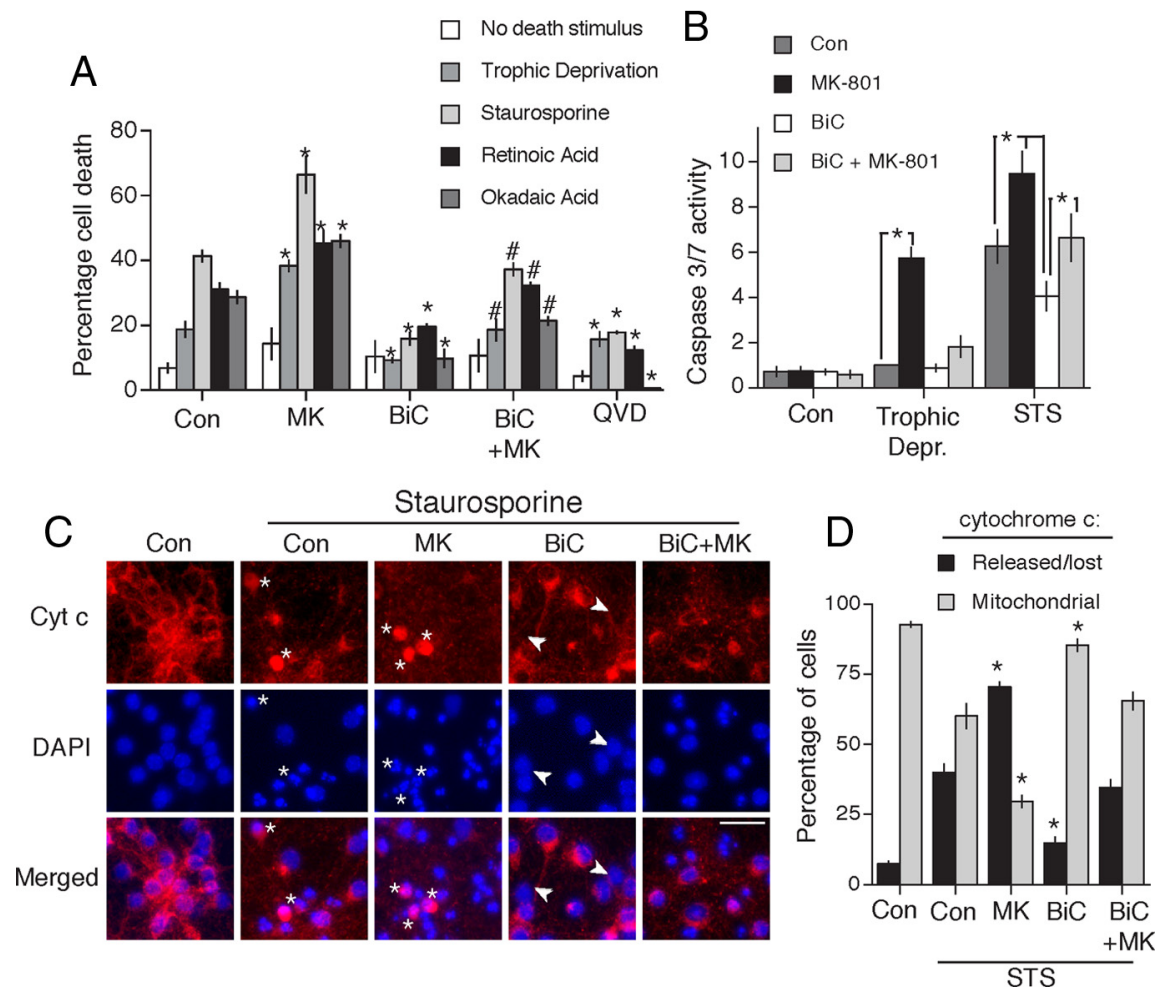

Figure 1. Neuroprotection afforded by synaptic activity. $A$, Synaptic activity protects neurons against inducers of apoptosis. Mouse cortical neurons were treated in the presence or absence of the indicated compounds [BiC/4-AP: bicuculline $(50 \mu \mathrm{M})$ plus 4-aminopyridine $(250 \mu \mathrm{M})$ is labeled as "BiC" in figures]; MK-801 used at $10 \mu \mathrm{m}$ here and throughout. These drugs were added $16 \mathrm{~h}$ before the addition of inducers of apoptosis (staurosporine, $100 \mathrm{~nm}$; retinoic acid, $5 \mu \mathrm{m}$; okadaic acid, $2 \mathrm{~nm}$ ). QVD-0ph was used at $50 \mu \mathrm{m}$ and added $1 \mathrm{~h}$ before the addition of inducers of apoptosis. After a further $24 \mathrm{~h}$, the neurons were fixed and levels of cell death calculated. In the case of trophic deprivation, neurons were subjected to $72 \mathrm{~h}$ in trophically deprived medium in the presence or absence of BiC, MK-801, or QVD-0ph. ${ }^{*} p<0.05$ (compared to levels of death in the equivalent control condition); ${ }^{\#} p<0.05$ compared to levels of death in the BiC/4-AP-stimulated neurons [two-way ANOVA followed by Fisher's LSD test $(n=4)$ ]. "No death stimulus" refers to neurons placed in standard transfection medium containing the insulin-transferrin-selenite supplement (trophic medium). B, (aspase-3/7 activation by apoptotic stimuli is suppressed by synaptic NMDAR activity. For the trophic deprivation model, neurons were treated with the indicated drugs for $48 \mathrm{~h}$ in trophically deprived medium. For the staurosporine (STS) model, neurons were treated with the indicated drugs for $16 \mathrm{~h}$ before treatment with staurosporine $(100 \mathrm{~nm})$ for a further $16 \mathrm{~h}$. Control condition is trophic medium as described in $A$. Caspase-3/7 activity was measured and normalized to protein levels ascertained by BCA assay. ${ }^{*} p<0.05$, one-way ANOVA followed by Fisher's LSD test here and elsewhere unless otherwise stated $(n=4)$. C, Synaptic NMDAR activity inhibits staurosporine-induced cytochrome ( (Cyt c) release. Neurons were treated as in A. Cytochrome c immunofluorescent staining was performed $16 \mathrm{~h}$ after exposure to staurosporine. Asterisks highlight cells exhibiting diffuse staining throughout the neuron, a transient state that precedes loss of staining and apoptosis. The white arrows highlight neurons where cytochrome c has been lost, but nuclear chromatin fragmentation has not taken place, indicative of protection downstream of cytochrome c release. Pictures are representative of four independent experiments. Scale bar, $40 \mu \mathrm{m}$. D, Quantification of data shown in C. For each condition, $\sim 1500$ cells were analyzed across four independent experiments. ${ }^{*} p<0.05$ compared to control condition (STS treated).

mixture (for RT reactions) or $1 \mu$ l of water (for no-RT control reactions). Reaction mixtures were mixed and spun down and incubated for 2 min at $25^{\circ} \mathrm{C}, 40 \mathrm{~min}$ at $42^{\circ} \mathrm{C}$, and $5 \mathrm{~min}$ at $95^{\circ} \mathrm{C}$. cDNA was stored at $-20^{\circ} \mathrm{C}$.

Dilutions of this cDNA were subsequently used for real-time PCR (cDNA equivalent to $6 \mathrm{ng}$ of initial RNA per $15 \mu \mathrm{l}$ qPCR reaction for all genes). qPCR was performed in an Mx3000P QPCR System (Stratagene) using Brilliant SYBR Green QPCR Master Mix (Stratagene) according to the manufacturer's instructions. Briefly, the required amount of template was mixed on ice with $2 \times$ Brilliant SYBR Green Master Mix, forward and reverse primers at $200 \mathrm{~nm}$ each final concentration, $30 \mathrm{~nm}$ final concentration ROX passive reference dye, and water to the required reaction volume. Technical replicates as well as no-template and no-RT negative controls were included, and at least three biological replicates were studied in each case. The sequences of the primers used are as follows: Puma: F-5'-CCT CAA CGC GCA GTA CG-3'; R-5'-TAGGCACCTAGTTGGGCTC-3'; Apaf1: F-5'-GAT GGT CCT TGC AGT TGA C-3'; R-5'-GAC ATT CCA CAC CTT CAC C-3'; Caspase 9:
F-5'-GTG GAC ATT GGT TCT GGC-3'; R-5'-GTT GAT GAT GAG GCA GTGG-3'; Caspase 3: F-5'-TCT TCA TCA TTC AGG CCT G-3'; R-5'-TGA ATT TCT CCA GGA ATA GTA ACC-3'; GAPDH: F- 5' -GGG TGT GAA CCA CGA GAA AT-3'; R-5'-CCT TCC ACA ATG CCA AAG TT-3'; 18 S rRNA: F-5' GTG GAG CGA TTT GTC TGG TT-3'; R-5' CAA GCT TAT GAC CCG CAC TT-3'; Trp53: F1-5'-GAT GAC TGC CAT GGA GGAG-3'; R1-5'-GAT CGT CCA TGC AGT GAGG-3'. The cycling program was $10 \mathrm{~min}$ at $95^{\circ} \mathrm{C} ; 40$ cycles of $30 \mathrm{~s}$ at $95^{\circ} \mathrm{C}, 40 \mathrm{~s}$ at $60^{\circ} \mathrm{C}$ with detection of fluorescence and $30 \mathrm{~s}$ at $72^{\circ} \mathrm{C} ; 1$ cycle (for dissociation curve) of $1 \mathrm{~min}$ at $95^{\circ} \mathrm{C}$ and $30 \mathrm{~s}$ at $55^{\circ} \mathrm{C}$ with a ramp up to $30 \mathrm{~s}$ at $95^{\circ} \mathrm{C}$ (ramp rate: $0.2^{\circ} \mathrm{C} / \mathrm{s}$ ) with continuous detection of fluorescence on the $55-95^{\circ} \mathrm{C}$ ramp. The data were analyzed using the MxPro QPCR analysis software (Stratagene). Expression of the gene of interest was normalized to GAPDH, a commonly used control. To confirm that normalizing to GAPDH is not introducing any systematic errors to our studies on activitydependent gene expression, we measured levels of another commonly used control gene (18S rRNA) compared to GAPDH under our different stimulation paradigms and found no significant differences. Compared to unstimulated neurons, GAPDH levels in MK-801treated neurons (normalized to $18 \mathrm{~S}$ rRNA) levels were $86 \pm 21 \%(p=0.55, t$ test $)$. In neurons stimulated for $4 \mathrm{~h}$ with $\mathrm{BiC} / 4-\mathrm{AP}$, GAPDH levels (normalized to $18 \mathrm{~S}$ rRNA) were $109 \pm 17 \%$ ( $p=0.72, t$ test $)$.

Transfection and following the fate of transfected cells. Neurons were transfected at DIV8 using Lipofectamine 2000 (Invitrogen). Transfection efficiency was $\sim 5 \%$. $>99 \%$ of eGFPexpressing transfected neurons were NeuN positive, and $<1 \%$ were GFAP positive (Soriano et al., 2008), confirming their neuronal identity. For the first set of neuronal viability assays, peGFP was used to track the fate of transfected neurons expressing the plasmid of interest (Puma vs globin control vs Puma- $\Delta \mathrm{BH} 3$ ). To ensure that GFP-positive neurons were also expressing the plasmid of interest, a favorable ratio was used (peGFP: plasmid of interest, 1:2). Coexpression at this ratio was confirmed in the case of pRFP (Papadia et al., 2008). Where used, siRNA was transfected at a final concentration of $100 \mathrm{~nm}$ (Puma target sequence: CCU GAU GCC CUC CGC UGU A). Dharmacon's nontargeting siRNA \#2 siRNA was used as control. Pictures of GFP-expressing neurons were taken on a Leica AF6000 LX imaging system, with a DFC350 FX digital camera. Using the automated cell-finder function within the Leica AF6000 software, images of transfected neurons were taken at the indicated intervals after transfection. Cell death at a particular time point was assessed by counting the number of surviving GFP-positive neurons. In the vast majority of cases, death was easily spotted as an absence of a healthy GFP-expressing cell where one once was. In place of the cell, there was in most cases $(>90 \%)$ evidence of death in the form of fragmented neurites, fluorescent cell debris, and an apoptotic nucleus (Papadia et al., 2008). This confirmed that the cells were genuinely dying as opposed to more unlikely scenarios such as quenching of eGFP fluorescence in a subpopulation of neurons. This is also underlined by the fact that death measured by this technique is blocked by caspase inhibitors (Papadia et al., 2008). 
For the experiments monitoring the effect of procaspase- 9 expression on neuronal apoptosis, neurons were transfected with peGFP plus either control vector or a vector encoding procaspase-9 (Origene). Neurons were immediately put in trophically deprived (TD) medium, and images of transfected cells were taken at $24 \mathrm{~h}$ after transfection, when levels of TD-induced death are very low. Images were then taken at 48 and $72 \mathrm{~h}$ after transfection. For each combination of plasmid(s) and stimulation condition, the fate of $\sim 130-200$ neurons was monitored over $4-6$ independent experiments.

Luciferase reporter assays. Firefly luciferase-based reporter gene constructs [Puma-Luc, Apaf1-Luc, and Casp9-Luc (Moroni et al., 2001; Tsujimoto et al., 2005; Wu et al., 2005)] were transfected along with a Renilla expression vector (pTK-RL). Neurons were stimulated (where appropriate) $24 \mathrm{~h}$ after transfection. Luciferase assays were performed using the Dual Glo assay kit (Promega) with Firefly luciferase-based reporter gene activity normalized to the Renilla control (pTK-RL plasmid) in all cases.

Statistical analysis, equipment, and settings. In all figures, the mean \pm SEM is shown. Statistical testing involved a 2 -tailed paired student $t$ test. For studies using multiple testing (e.g., the use of two pairs of siRNA, or comparisons between multiple deletion/mutant luciferase reporters constructs), we used a one-way ANOVA followed by Fisher's LSD post hoc test. For Western blots, we used chemiluminescent detection on Kodak $\mathrm{X}$-Omat film. Appropriate exposures were taken such that bands were not saturated. For figure preparation of example Western blots, linear adjustment of brightness/contrast was applied (Photoshop) equally across the entire image, taking care to maintain some background intensity. Pictures of transfected neurons were taken on a Leica AF6000 LX imaging system, with a DFC350 FX digital camera. The DFC350 FX digital camera is a monochrome camera, and so colored images (e.g., of green fluorescent protein) essentially involve taking a black and white image (using the appropriate filter set) and applying a color to the image after capture. All luminescent assays were performed on a FLUOstar OPTIMA (BMG Labtech). Light collection time and gain were set such that counts were substantially lower than the maximum level collectable.

\section{Results}

\section{Suppression of cytochrome $c$ release, caspase activation, and} apoptosis by synaptic NMDAR activity

To analyze the molecular mechanisms involved in synaptic activity-dependent neuroprotection, we recapitulated activitydependent neuroprotection in vitro using established models for neuronal apoptosis (Papadia et al., 2005). We used an established method of network disinhibition to enhance synaptic activity, by applying the $\mathrm{GABA}_{\mathrm{A}}$ receptor antagonist bicuculline. This treatment results in synchronized bursts of action potentials (APs) that are associated with intracellular $\mathrm{Ca}^{2+}$ transients dependent on influx through NMDA receptors, as well as release from internal stores and some influx through voltage-gated channels (Hardingham et al., 2001). The $\mathrm{K}^{+}$channel antagonist 4-aminopyridine was coapplied with bicuculline to enhance burst frequency (Hardingham et al., 2001) (hereafter BiC/4-AP).

$\mathrm{BiC} / 4$-AP treatment results in the protection of mouse and rat cortical neurons from apoptosis due to oxidative stress by enhancement of intrinsic antioxidant defenses (Papadia et al., 2008). However, we wanted to know whether anti-apoptotic mechanisms also contribute to activity-dependent neuroprotection, in addition to antioxidant mechanisms. To test the general anti-apoptotic action of $\mathrm{BiC} / 4-\mathrm{AP}$-induced activity, we used a range of different insults: trophic deprivation, staurosporine, retinoic acid, and okadaic acid, which all induce apoptosis which is blocked by the pan-caspase inhibitor QVD-Oph [Fig. $1 A$ and Papadia et al. (2008) ]. We observed that BiC/4-AP-induced burst activity protected mouse cortical neurons against all of these insults (Fig. 1A), consistent with studies using other cell types such as rat hippocampal neurons (Hardingham et al., 2002; Papadia et al., 2005).

These apoptosis inducers are widely used activators of intrinsic apoptosis involving cytochrome $c$ release and caspase activation and operate via multiple effects that contribute to cell death. However, a common theme in these (and inducers in general) is to alter the balance in the expression and/or activity of pro- and anti-apoptotic bcl2 family members in favor of the proapoptotic members ((Fujimura et al., 2003; Chen et al., 2005; Akhtar et al., 2006; Mouratidis et al., 2006; Jayaraj et al., 2009; Roy et al., 2009) and references therein). The observation that the anti-apoptotic effects of neuronal activity are not insult-specific (Fig. $1 A$ ) points to the existence of activity-induced events that target fundamental parts of the intrinsic apoptosis pathway (see below).

The efficacy of this protection, quantified by assessing nuclear morphology, was confirmed electrophysiologically. Focusing on the $\mathrm{BiC} / 4$-AP-treated neurons that were exposed to an ordinarily toxic dose of staurosporine ( $100 \mathrm{nM})$, we injected current into the rescued cells (with $300 \mathrm{~ms}$ pulses at $1 \mathrm{~Hz}$ ) to bring them to threshold. In current clamp configuration, all surviving cells studied fired action potential bursts when depolarized beyond $-40 \mathrm{mV}$, as was observed with non-staurosporine-treated neurons (see examples in supplemental Fig. S1, available at www.jneurosci.org as supplemental material). The protection afforded by $\mathrm{BiC} / 4-\mathrm{AP}$ treatment was reduced by the coapplication of $\mathrm{MK}-801$, demonstrating the importance of NMDAR activity in AP burst activityevoked neuroprotective signaling, as shown previously (Papadia et al., 2005).

Untreated cortical neurons in culture experience significant levels of spontaneous synaptic (but not extrasynaptic) NMDAR activity (Papadia et al., 2008). Although this activity is more modest than that experienced in response to $\mathrm{BiC} / 4-\mathrm{AP}$ treatment, its pro-survival effect can be studied by blocking it with MK-801. Blockade of spontaneous NMDAR activity with MK-801 exacerbated death in these models of apoptosis (Fig. $1 A$ ). Of particular note, the level of neuronal apoptosis in untreated neurons subject to $72 \mathrm{~h}$ of trophic deprivation was relatively low but was also dramatically increased by MK-801 treatment (Fig. $1 A$ ). Thus, the level of synaptic NMDAR activity [namely, comparing none (MK-801) vs low-level spontaneous activity (untreated control) vs $\mathrm{AP}$ burst-induced activity $(\mathrm{BiC} / 4-\mathrm{AP})]$ correlated well with resistance to a variety of apoptotic insults. Consistent with its protective effect, $\mathrm{BiC} / 4$-AP treatment blocked caspase-3/7 activation induced by staurosporine treatment (Fig. $1 B$ ), as we recently found in the case of peroxide treatment (Papadia et al., 2008). The protective effect of $\mathrm{BiC} / 4-\mathrm{AP}$ treatment was reversed by MK-801 (Fig. 1A). Furthermore, blockade of spontaneous NMDAR activity by MK-801 caused an increase in staurosporine-induced caspase-3/7 activity and strongly induced caspase-3/7 activity in trophically deprived neurons (Fig. $1 B$ ). Thus, synaptic NMDAR activity suppresses the activation of executioner caspases following an apoptotic insult.

Release of mitochondrial cytochrome $c$ into the cytoplasm is an important apoptotic control point (Meier and Vousden, 2007) that leads to the formation of the Apaf-1-containing apoptosome and recruitment/activation of procaspase- 9 , an initiator caspase. Cytochrome $c$ release is characterized by loss of punctate mitochondrial localization and appearance of diffuse cellular staining, followed quickly by complete loss of staining as the cell undergoes apoptosis (Wyttenbach and Tolkovsky, 2006). We found that exposure of neurons to staurosporine promoted cytochrome $c$ release from mitochondria: cytochrome $c$ staining was either absent in apoptotic cells or diffuse throughout the cell (Fig. 1C,D). 
A

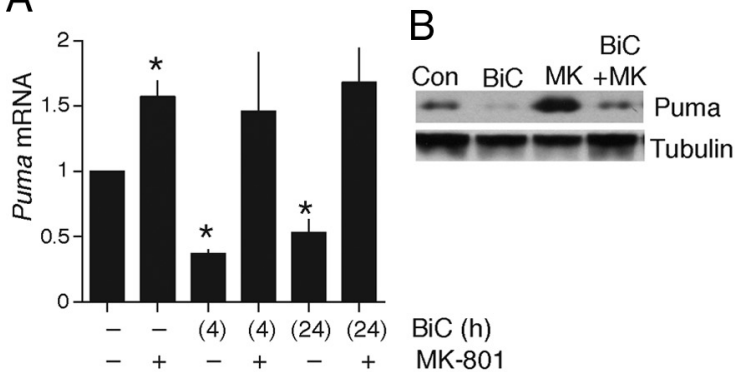

C

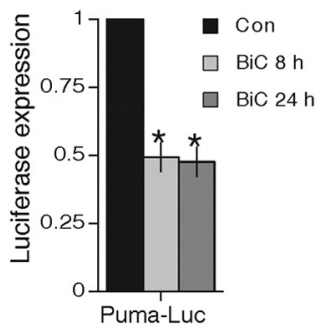

E

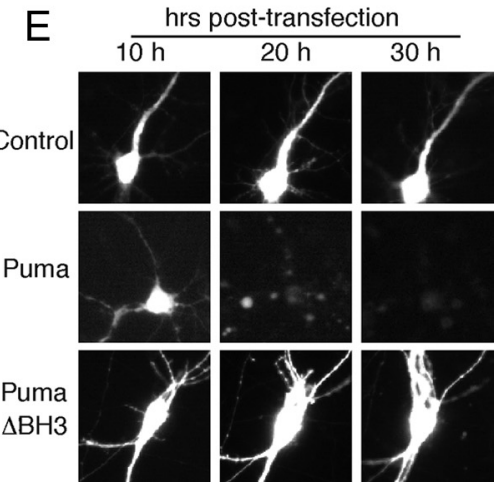

Figure 2. Activity-dependent suppression of the proapoptotic gene Puma protects neurons. $A$, Activity-dependent suppression of the proapoptotic gene Puma. QRT-PCR analysis of Puma expression in cortical neurons treated with the indicated drugs. $\boldsymbol{B}$, Western blot illustrating regulation of Puma expression at the protein level. $\boldsymbol{C}$, The Puma promoter is sufficient to confer activity-dependent suppression on a reporter gene. Neurons were transfected with a Puma-luciferase reporter, plus a TK-Renilla control vector. At $24 \mathrm{~h}$ after transfection, neurons were stimulated for the indicated times, and firefly luciferase reporter activity was measured, normalized to the Renilla control. ${ }^{*} p<0.05$, Student two-tailed $t$ test $(n=4)$. D, E, Puma expression is sufficient to induce apoptosis in cortical neurons. Neurons were transfected with the indicated vectors, plus a vector encoding eGFP as a transfection marker. Transfected neurons were identified after $10 \mathrm{~h}$, and their fate was monitored at 20 and 30 h. ${ }^{*} p<0.05(n=3)$.

Blockade of spontaneous NMDAR activity with MK-801 resulted in an increase in the proportion of staurosporine-treated neurons exhibiting cytochrome $c$ loss (Fig. 1C,D). With $\mathrm{BiC} / 4$ AP-stimulated neurons exposed to staurosporine, a far smaller percentage of neurons exhibited cytochrome $c$ release than with control neurons [ $15 \pm 2 \%$ compared to $40 \pm 3 \%, p<0.05$ ( $n=$ 4 ) (Fig. 1D), clearly indicative of protective mechanisms upstream of release. However, considering only the cytochrome $c$-negative cells in isolation, a larger proportion of these had normal, nonpyknotic nuclear morphology in the BiC/4-APstimulated group than in the control group [18 $\pm 2 \%$ compared to $5 \pm 2 \%, p<0.05(n=4)$ ] (Fig. $1 C$, white arrows), indicative of some inhibition of apoptotic processes downstream of cytochrome $c$ release. Mechanisms downstream of cytochrome $c$ release could involve regulation of apoptosome components, Apaf-1 and caspase-9, or other events downstream of caspase- 9 activation, as illustrated by the fact that the pan-caspase inhibitor QVD-Oph also inhibits nuclear pyknosis downstream of cytochrome $c$ release (supplemental Fig. S2a, available at www. jneurosci.org as supplemental material). Regulation of pro- and anti-apoptotic members of the $\mathrm{Bcl} 2$ family offer a potential mechanism by which synaptic activity could prevent cytochrome $c$ release following an insult. Qualitatively similar results regarding cytochrome $c$ were obtained using hydrogen peroxide as the apoptosis-inducing agent (supplemental Fig. S2 $b$, available at www.jneurosci.org as supplemental material). In this instance activity-dependent enhancement of intrinsic antioxidant defenses (Papadia et al., 2008) may also contribute to prevention of cytochrome $c$ release, in addition to the general anti-apoptotic mechanisms under investigation here.

The release of Smac/Diablo from mitochondria can cooperate with cytochrome $c$ release in promoting apoptosis by suppressing the inhibitors of apoptosis (IAPs). However, in our hands, mitochondrial localization of Smac/Diablo was not perturbed until after cytochrome $c$ release, and in the large majority of cases, after nuclear pyknosis (G. E. Hardingham, unpublished observations), suggesting that Smac/Diablo release is not a key apoptotic trigger in DIV10 cortical neurons.

\section{Activity-dependent neuroprotection involves suppression of Puma expression}

Puma is a pro-death BH3-only domain member of the $\mathrm{Bcl} 2$ superfamily, which is an important regulator of neuronal apoptosis in response to a variety of injuries, including oxidative stress, staurosporine, and trophic deprivation (Wyttenbach and Tolkovsky, 2006; Kieran et al., 2007; Steckley et al., 2007). We found that inducing $\mathrm{AP}$ bursting with $\mathrm{BiC} / 4-\mathrm{AP}$ treatment resulted in the downregulation of Puma mRNA and protein expression, an effect reversed by coapplication of MK-801 (Fig. $2 A, B)$. Moreover, BiC/4-AP treatment reduced Puma upregulation by staurosporine in an NMDAR-dependent manner (supplemental Fig. S3, available at www.jneurosci. org as supplemental material).

In addition to the Puma-suppressing effects of enhancing synaptic NMDAR activity by $\mathrm{BiC} / 4-\mathrm{AP}$ stimulation, we investigated whether spontaneous synaptic NMDAR activity in untreated control cultures has a Puma-suppressing effect. We found that blockade of spontaneous synaptic NMDAR activity caused an upregulation of Puma expression. The most likely mechanism of activity-dependent suppression of Puma expression is transcriptional, although other potential mechanisms exist, such as regulation of mRNA stability. Consistent with a direct effect on the transcriptional activity of the Puma promoter, activity of a luciferase-based reporter of the Puma promoter (Puma-Luc (Wu et al., 2005)), was suppressed by BiC/4-AP stimulation (Fig. 2C).

Suppression of physiological NMDAR activity promotes neuronal loss and exacerbates neurodegeneration in vivo (Ikonomidou et al., 1999, 2000; Adams et al., 2004; Tashiro et al., 2006). We therefore tested whether physiological NMDAR activity also suppresses Puma expression in vivo. P6 mice were injected with MK-801, which we recently showed induces widespread TUNELpositive cell death in the cortex $24 \mathrm{~h}$ after injection (Papadia et al., 2008) as was reported for rat brains (Ikonomidou et al., 1999). Analysis of Puma expression in advance of this time (at $12 \mathrm{~h}$ after injection) revealed significant upregulation by MK-801 administration $(2.2 \pm 0.2$-fold, $p<0.05)$, indicative of a suppressive effect of physiological NMDAR activity on Puma expression in vivo.

While transsynaptic activation of synaptic NMDARs is antiapoptotic, chronic activation of all (synaptic and extrasynaptic) NMDARs by bath application of glutamate/NMDA is not (Hardingham et al., 2002). Moreover, synaptic and bath activation of NMDARs promote very different transcriptional re- 
sponses (Zhang et al., 2007). We therefore tested whether transsynaptic activation of synaptic NMDARs is critical for NMDAR-dependent suppression of Puma expression. We bath applied a range of glutamate doses to determine whether any dose is able to result in the transcriptional repression of the apoptotic genes described in this study. Glutamate was applied in the presence of TTX to prevent preferential activation of synaptic NMDARs (Soriano et al., 2006). We found that no dose of glutamate resulted in significant suppression of Puma expression (supplemental Fig. S4, available at www.jneurosci.org as supplemental material), suggesting that NMDAR-dependent suppression of Puma is restricted to the transsynaptic activation of synaptic NMDARs, and is not a preconditioning-type effect in response to subtoxic glutamate exposure.

Studies have shown that expression of Puma is sufficient to induce apoptosis in immature cortical neurons [E15.5 cultured for 3-4 d in vitro (Steckley et al., 2007; Uo et al., 2007)] and in DIV6 postnatal cortical neurons (Wong et al., 2005). To confirm this in our system, neurons were transfected with a vector encoding wild-type Puma driven by a constitutively active promoter, plus a vector encoding eGFP to identify transfected cells. At $10 \mathrm{~h}$ after transfection, GFP-positive neurons were observed. By observing these cells at 20 and then $30 \mathrm{~h}$ after transfection, we found that they die rapidly even when held in trophic medium (Fig. $2 D, E)$. In contrast, when the neurons were transfected with either a control ( $\beta$-globin) vector or a vector encoding a mutant form of Puma lacking its pro-death $\mathrm{BH} 3$ domain, Puma- $\Delta \mathrm{BH} 3$ (Yu et al., 2001; Wong et al., 2005), these cells did not die (Fig. $2 D, E)$. Furthermore, we observed more control- and Puma$\Delta \mathrm{BH} 3$ transfected cells per field at $10 \mathrm{~h}$ than Puma-expressing cells, suggesting that many Puma-expressing cells were already dead even at $10 \mathrm{~h}$ after transfection. The fact that Puma is sufficient to trigger apoptosis indicates that its suppression may have a profound protective effect.

We investigated the importance of synaptic NMDAR activitydependent Puma suppression in activity-dependent neuroprotection by studying cortical neurons cultured from Puma-deficient mice. We found that levels of apoptosis were significantly reduced in Puma-deficient neurons subjected to staurosporine treatment (Fig. 3A). Not only did Puma-deficient neurons treated with staurosporine show normal nuclear morphology, but the neurons appeared healthy under phase contrast (Fig. 3B) and could all fire action potentials when patched and injected with current (supplemental Fig. S5, available at www.jneurosci. org as supplemental material). Moreover, mitochondrial cytochrome $c$ localization was retained in Puma-deficient neurons treated with staurosporine, as would be expected given its position in the apoptosis pathway (supplemental Fig. S6, available at www.jneurosci.org as supplemental material). Also of note, expression of Puma (but not Puma- $\Delta \mathrm{BH} 3$ in Puma-deficient neurons effectively triggered apoptosis (supplemental Fig. S7, available at www.jneurosci.org as supplemental material), indicating that developmental loss of Puma has not caused disruption to the rest of the apoptosis machinery.

We also observed that MK-801 did not exacerbate staurosporineinduced death as it does in wild-type cells (Fig. 3A). Puma deficiency also blocked apoptosis induced by prolonged exposure of neurons to MK-801 in trophically deprived medium (Fig. $3 C, D)$. Thus, Puma deficiency abrogates the need for neuroprotective synaptic NMDAR activity, consistent with the hypothesis that Puma suppression is a key protective mechanism induced by synaptic NMDAR activity. To offset the possibility that Puma $-/-$ neurons had a developmental deficiency in their apoptosis pathway, we also studied the effect of siRNA-directed against Puma in wild-type neurons, which protected neurons against MK-801 and staurosporine-induced cell death, compared to a control siRNA (supplemental Fig. S8, available at www. jneurosci.org as supplemental material). This effect could be overcome by overexpressing human Puma, which contains several mismatches at the targeted regions (data not shown). Thus, the Puma siRNA data are consistent with the data obtained from Puma knock-out neurons.

Finally, we investigated neuronal death in response to hydrogen peroxide. In this model of apoptosis, we found that $\mathrm{BiC} / 4$ AP-induced synaptic activity still exerted some protection in Puma-deficient neurons, despite dramatically lower levels of death overall (supplemental Fig. S9, available at www.jneurosci. org as supplemental material). This is consistent with neuroprotection against oxidative stress-induced apoptosis involving more than just Puma downregulation. Indeed, we know this to be the case: intrinsic antioxidant defenses are enhanced by synaptic NMDAR activity (Papadia et al., 2008) and are likely to act in concert with anti-apoptotic Puma suppression.

\section{Synaptic activity can promote survival downstream of Puma expression}

We observed that AP-bursting appears to block chromatin fragmentation in a few cases without preventing cytochrome $c$ release (Fig. 1D). We therefore wanted to determine whether AP bursting could inhibit apoptotic processes downstream of Puma upregulation. To do this, we transfected neurons with a Pumaencoding vector, and determined the effect of AP bursting on the number of Puma-expressing cells visible at $10 \mathrm{~h}$ after transfection. The cultures were treated with $\mathrm{BiC} / 4-\mathrm{AP}$ before, during, and after transfection. We observed that AP bursting induced a specific increase in eGFP/Puma-expressing cells. We confirmed that the eGFP-positive neurons were immunopositive for Puma (supplemental Fig. S10, available at www.jneurosci.org as supplemental material). We did not observe any increase in the numbers of globin- or Puma- $\Delta \mathrm{BH} 3$-expressing neurons as expected, since these cells were not dying. Nevertheless, to control for any subtle nonspecific effect of AP bursting, we expressed the effect of $\mathrm{BiC} /$ 4-AP treatment on the number of Puma-expressing cells relative to its effect on both globin- and Puma- $\Delta \mathrm{BH} 3$-expressing neurons (Fig. 3E). The effect of BiC/4-AP-induced AP bursting was to specifically increase the number of Puma-expressing neurons (both relative to control and Puma- $\Delta \mathrm{BH} 3$-expressing neurons), indicating that burst activity is inhibiting Puma-induced apoptosis.

To obtain a better idea of the extent to which AP burst activity inhibits Puma-induced apoptosis, we compared its effect to that of QVD-Oph treatment, which inhibits caspase-dependent apoptosis and so should also inhibit the death of Puma-expressing neurons in the short term. As was observed with BiC/4-AP treatment, QVD-Oph resulted in a specific increase in Pumaexpressing neurons observed relative to its effect on both globin- and Puma- $\Delta \mathrm{BH} 3$-expressing neurons (Fig. $3 E$ ). The effect of BiC/4-AP treatment was $\sim 60 \%$ of that of the pancaspase inhibitor, indicative of substantial inhibition of Pumainduced apoptosis.

We next investigated whether the inhibition/delay of Pumainduced apoptosis by synaptic activity is exerted upstream or downstream of cytochrome $c$ release. We found that $67 \pm 7 \%$ of Puma-overexpressing, BiC/4-AP-stimulated neurons exhibited cytochrome $c$ loss (Fig. $3 F, G$ ). By comparison, only $5 \pm 3 \%$ of neurons expressing the inactive mutant Puma- $\Delta \mathrm{BH} 3$ exhibited apparent cytochrome $c$ loss. We compared these figures to those 


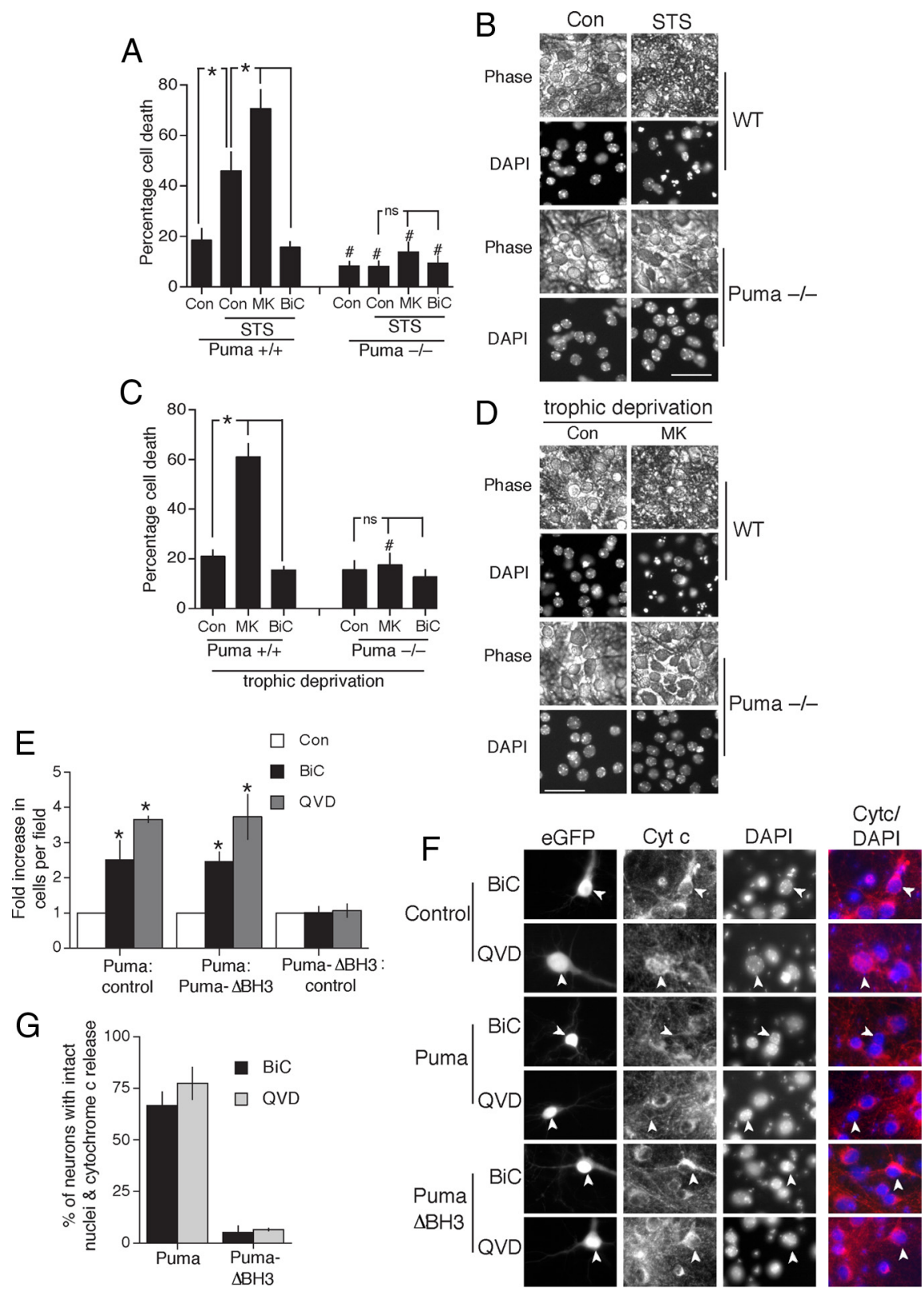

Figure 3. Synaptic activity can suppress the proapoptotic effect of Puma upregulation. $\boldsymbol{A}, \boldsymbol{B}$, The neuroprotective effect of synaptic activity against staurosporine-induced apoptosis is occluded by Puma deficiency. Both wild-type and Puma-deficient neurons were stimulated as indicated for $16 \mathrm{~h}$ before the addition of staurosporine (100 $\mathrm{nm}$ ) where indicated, for a further $24 \mathrm{~h}$. After $24 \mathrm{~h}$ cell death was assessed. ${ }^{*} p<0.05(n=4)$ indicates stimulus-dependent differences $(n=4)$. ${ }^{*} p<0.05$ indicates differences due to genotype (i.e., compared to $+/+$ neurons treated in the same way); "ns" indicates no significant statistical difference. $\boldsymbol{B}$, Example phase-contrast pictures alongside the same field of cells after fixation and DAPI staining of nuclei. Scale bar, $50 \mu \mathrm{m}$. C, D, The neuroprotective effect of synaptic activity against trophic deprivation-induced apoptosis is occluded by Puma deficiency. Wildtype and Puma-deficient neurons were treated as indicated for $72 \mathrm{~h}$ in trophically deprived medium, after which cells were fixed and levels of cell death assessed. ${ }^{*} p<0.05(n=4) .{ }^{*} p<0.05(n=4)$ indicates stimulus-dependent differences $(n=4) .{ }^{*} p<0.05$ indicates differences due to genotype (i.e., compared to $+/+$ neurons treated in the same way); "ns" indicates no significant statistical difference. D, Example phase-contrast pictures alongside the same field of cells after fixation and DAPI staining of nuclei. Scale bar, $50 \mu \mathrm{m}$. E, Synaptic activity can suppress the proapoptotic effect of Puma upregulation. Neurons were treated where indicated with BiC/4-AP starting $24 \mathrm{~h}$ before being transfected with peGFP plus vectors encoding either Puma, $\beta$-globin, or Puma- $\Delta \mathrm{BH}$. Where used, $\mathrm{QVD}-0 \mathrm{ph}$ was applied to neurons $1 \mathrm{~h}$ before transfection. For each expression vector, and for each treatment, the number of viable neurons per field was analyzed at $10 \mathrm{~h}$ after transfection. The effect of BiC/4-AP-induced AP burst activity, or the effect of QVD-Oph, on the number of Puma-expressing neurons seen is expressed relative to the effect of these treatments on the number of neurons expressing the two control vectors ( $\beta$ globin and Puma- $\Delta \mathrm{BH} 3) .{ }^{*} p<0.05(n=6) . \boldsymbol{F}, \mathbf{G}$, Suppression of Puma-induced apoptosis by synaptic activity or caspase inhibition is downstream of cytochrome crelease. Neurons are shown expressing eGFP plus either control vector ( $\beta$-globin), Puma or Puma- $\Delta B H 3$. To inhibit Puma-induced apoptosis neurons were either pretreated with BiC/4-AP or QVD-0ph, as described in the text. At $10 \mathrm{~h}$ after transfection neurons were fixed and processed for cytochrome c immunofluorescence. $G$, Quantification of the percentage of viable Puma and Puma $\triangle \mathrm{BH}$ 3-expressing neurons exhibiting cytochrome crelease at $10 \mathrm{~h}$ after transfection. $60-100$ cells were analyzed for each treatment across three independent experiments. obtained in neurons treated with the pan-caspase inhibitor QVD-Oph, since protection afforded by this inhibitor would be expected to be exerted downstream of cytochrome $c$ release, finding that $77 \pm 8 \%$ of Puma-overexpressing, QVD-treated neurons exhibited cytochrome $c$ loss, a similar figure to that obtained with $\mathrm{BiC} / 4$-AP-treated neurons (Fig. $3 F, G$ ). We conclude from this that synaptic activity does indeed inhibit Pumainduced neuronal death by acting downstream of cytochrome $c$ release, suggesting the existence of an additional anti-apoptotic pathway.

\section{Synaptic activity suppresses expression} of Apaf-1 and procaspase- 9

Cytochrome $c$ release into the cytoplasm and its binding to Apaf-1 triggers Apaf-1 multimerization (forming the apoptosome). The apoptosome then induces activation of procaspase-9, the initiator caspase (Meier and Vousden, 2007). Synaptic NMDAR activity reduced levels of caspase- 9 activity following trophic deprivation and $100 \mathrm{~nm}$ staurosporine (Fig. $4 A$ ), similar to its effect on caspase-9 activation following peroxide treatment (Papadia et al., 2008). While this is undoubtedly due largely to prevention of cytochrome $c$ release, we also examined whether expression of Apaf-1 or caspase- 9 are altered by synaptic activity, since this could represent a control point downstream of cytochrome $c$ release. We found that expression of genes encoding procaspase-9 (Casp9) and Apaf-1 (Apaf1) were strongly suppressed by AP bursting (Fig. 4B). Activity of luciferase-based reporters of both the Casp9 and Apaf1 promoters (Moroni et al., 2001; Tsujimoto et al., 2005) were also suppressed by AP bursting (Fig. 4C), strongly suggesting a direct effect on the transcription of these genes (as opposed to any posttranscriptional effects). The suppression of Apaf-1 and procaspase- 9 expression by firing activity raises the possibility that a stronger or more widespread mitochondrial dysfunction may be required to trigger apoptosis in electrically active neurons. In neuronal cells, developmentally regulated lowering of Apaf-1 expression is known to increase resistance to release of cytochrome $c$ (Potts et al., 2003; Wright et al., 2004). We therefore investigated whether lowered levels of procaspase- 9 expression can also impede apoptosis in neurons. We hypothesized that during progressive neuronal degeneration, such as that induced by prolonged trophic deprivation, the level of procaspase- 9 expression may 

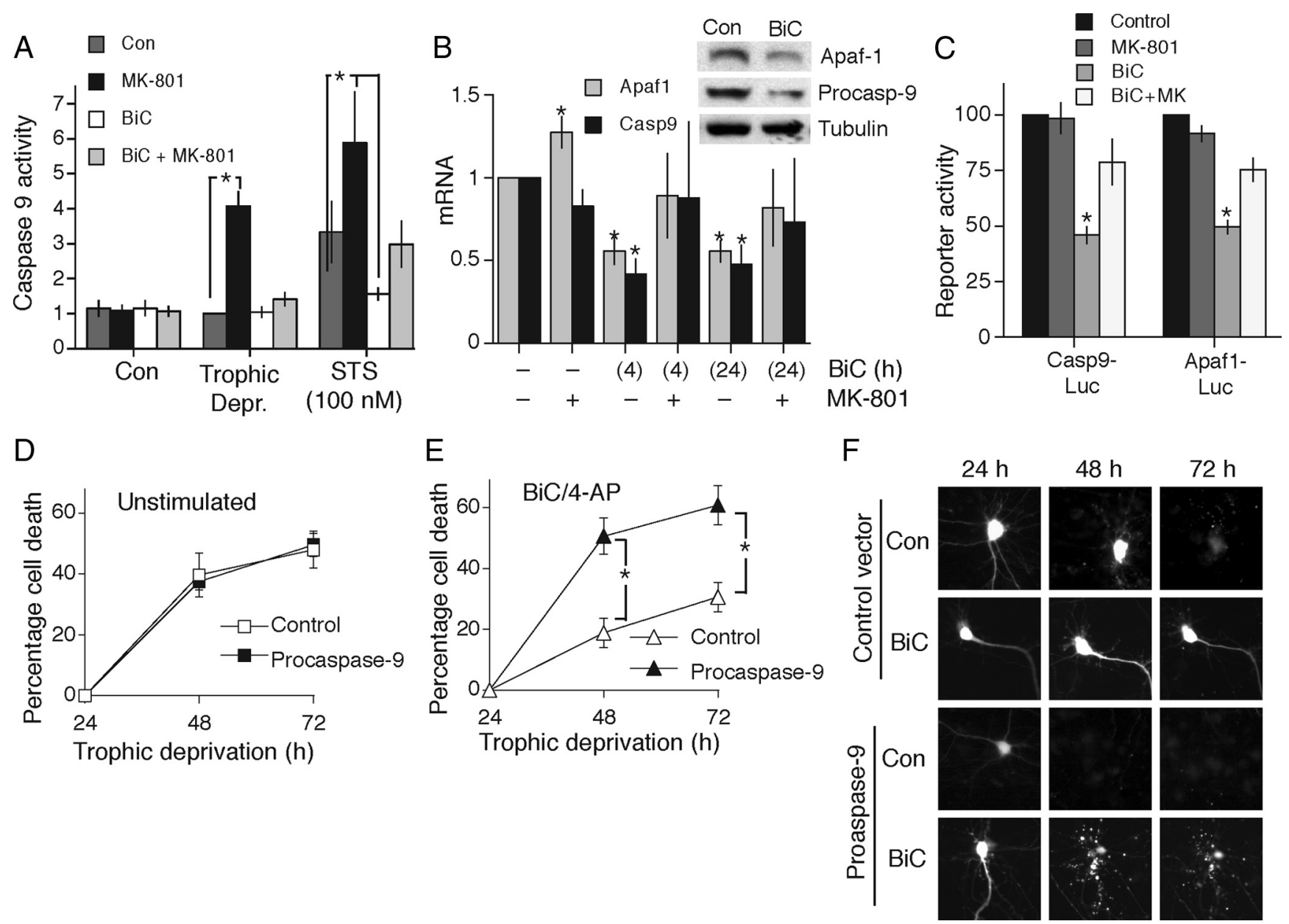

Figure 4. Synaptic activity suppresses the expression of Apaf-1 and procaspase-9. A, Synaptic NMDAR activity inhibits activation of caspase-9 in response to an apoptotic insult. Neurons were treated with the indicated compounds as described in Figure 1 A. Caspase- 9 activity was measured after $48 \mathrm{~h}$ trophic deprivation, or $16 \mathrm{~h}$ staurosporine treatment. ${ }^{*} p<0.05(n=4) . \boldsymbol{B}$, Synaptic NMDAR activity suppresses expression of apoptosome components. QRT-PCR analysis of Apaf1 and Casp 9 expression in neurons. ${ }^{*} p<0.05(n=4)$. Inset shows example Western blot illustrating $\mathrm{BiC} / 4$-AP-induced suppression of protein expression. C, Promoter regions of Apaf1 and Casp9 confer activity-dependent suppression on a luciferase reporter gene. Neurons were transfected with the indicated reporters, plus a TK-Renilla control vector. At $24 \mathrm{~h}$ after transfection, neurons were stimulated for the indicated times and firefly luciferase reporter activity was measured, normalized to the Renilla control. ${ }^{*} p<0.05(n=3)$. $\boldsymbol{D}, \boldsymbol{E}$, Overexpression of procaspase-9 accelerates apoptosis in AP-bursting but not control neurons. Neurons expressing eGFP plus either a control vector ( $\beta$ globin) or a vector encoding procaspase-9 were placed in trophically deprived medium and either left unstimulated $(\boldsymbol{D})$ or treated with BiC/4-AP to induce AP bursting $(\boldsymbol{E})$. Pictures of neurons were taken at $24 \mathrm{~h}$ and then their viability was monitored at $24 \mathrm{~h}$ intervals. ${ }^{*} p<0.05(n=5)$. $\boldsymbol{F}$, Example pictures relating to $\boldsymbol{D}$ and $\boldsymbol{E}$.

influence the rate of apoptosis. To test whether levels of procaspase- 9 can influence the rate of death, we overexpressed procaspase- 9 and monitored the rate of neuronal death during trophic deprivation. We found that in AP bursting neurons, the rate of apoptosis was significantly increased by overexpressing Casp9 (Fig. 4E, F), an effect reversed by MK-801 (supplemental Fig. S12, available at www.jneurosci.org as supplemental material). However, procaspase-9 overexpression did not alter the rate of apoptosis in unstimulated neurons (Fig. $4 D, F$ ). Together these experiments suggest that the level of procaspase-9 expression is not a limiting factor in apoptosis in electrically quiet neurons, but that in firing neurons, where procaspase- 9 levels are suppressed (as indeed is Apaf-1), it may become limiting.

\section{Synaptic activity does not exert significant protection downstream of caspase- 9 activation}

We next wanted to determine whether synaptic activity could exert any anti-apoptotic effects downstream of caspase-9 activation. Several potential control points exist, such as changes in expression of IAPs (Potts et al., 2003) or of executioner caspases. QRT-PCR analysis revealed that AP bursting caused the transcrip- tional suppression of the gene encoding procaspase-3 (Casp3), one of the executor caspases downstream of caspase-9 activation (Fig. $5 A$ ). This raised the possibility that apoptosis may be inhibited or slowed downstream of caspase- 9 activation.

To investigate protection downstream of caspase- 9 activation, we used an inducible form of caspase-9 [icasp9 (Nör et al., 2002)] that comprises the procaspase- 9 zymogen fused to a modified version of FK-506 binding protein. This undergoes dimerization when cells are treated with a cell-permeable dimerizer: a bivalent, modified version of FK-506, AP20187 (Ariad). Upon dimerization, icasp9 activates its dimer partner, releasing active caspase-9. In icasp9-expressing cortical neurons, addition of AP20187 resulted in cell death that was blocked by QVD-Oph (Fig. 5B). Neither dimerizer alone nor icasp9 expression alone affected viability (Fig. 5B). AP20187 killed icasp9-expressing neurons in a dose-dependent manner at very low concentrations (Fig. 5C). Importantly, BiC/4-AP-induced synaptic activity did not reduce cell death caused by artificial caspase- 9 activation, even at threshold concentrations of AP20187 (Fig. 5C). This experiment indicates that protective pathways downstream of caspase- 9 ac- 

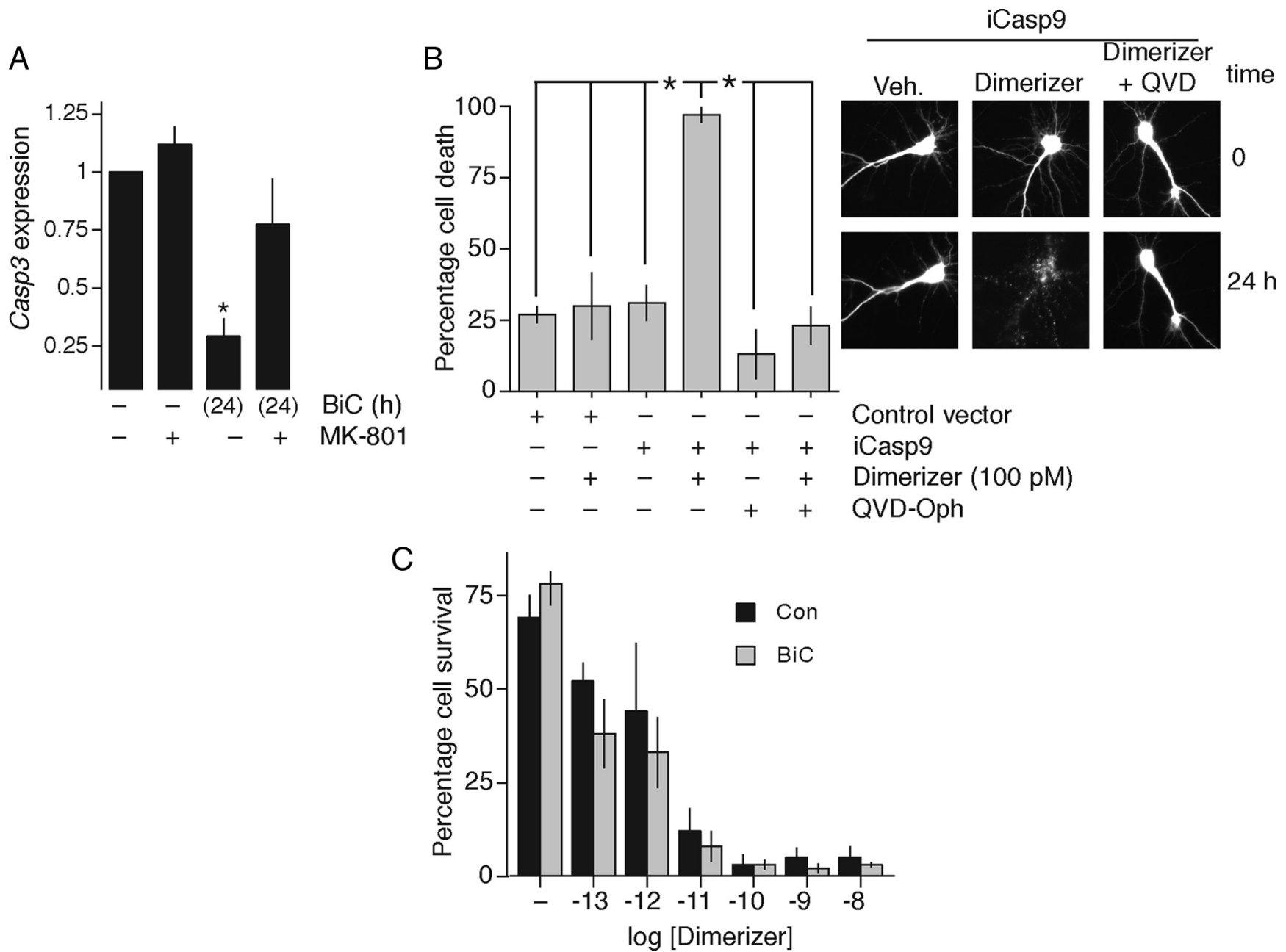

Figure 5. Synaptic activity does not exert protection downstream of caspase- 9 activation. $\boldsymbol{A}, \mathrm{QRT}-\mathrm{PCR}$ analysis of Casp3 expression in neurons stimulated as indicated. ${ }^{*} p<0.05(n=3)$. $\boldsymbol{B}$, The inducible caspase-9 system enables neurons to be killed by treatment with the dimerizer drug AP20187. Neurons were transfected with peGFP plus either control or icaspase-9 encoding vectors. At $24 \mathrm{~h}$ after transfection pictures of neurons were taken before the treatment, where indicated, with AP20187 (100 pM), to cause dimerization/activation of icaspase-9. Cell death was assessed after a further $24 \mathrm{~h}$. Where used, QVD-0ph was applied $1 \mathrm{~h}$ before AP20187. ${ }^{*} p<0.05(n=4)$. Inset shows example pictures. C, Synaptic activity cannot protect against icaspase-9-induced apoptosis. Neurons were transfected as in $\boldsymbol{B}$ and immediately left either unstimulated or treated with $\mathrm{BiC} / 4-\mathrm{AP}$ to induce burst activity. At $24 \mathrm{~h}$ after transfection pictures of cells were taken before treatment with the indicated concentrations of AP20187. Cell death was assessed after a further $24 \mathrm{~h}(n=4)$.

tivation are not a significant aspect of the anti-apoptotic effects of synaptic activity.

\section{Activity-dependent suppression of Puma, Apaf1, and Casp9} transcription in cortical neurons is not via p53 inhibition It was recently shown that synaptic activity induces suppression of the proapoptotic transcription factor p53 in hippocampal neurons, and that knockdown of $\mathrm{p} 53$ is sufficient to protect neurons against apoptotic insults (Lau and Bading, 2009). We therefore investigated whether suppression of p53 is the mechanism by which synaptic activity suppresses expression of Puma, Apaf1, and Casp9 in cortical neurons, especially since p53 is implicated in the regulation of Puma and Apaf1 (Moroni et al., 2001; Yu et al., 2001). BiC/4-AP-induced synaptic activity suppressed p53 expression by $\sim 30 \%$ in cortical neurons, to levels that remain higher than in neurons cultured from p53 heterozygous + / mice (Fig. 6A). Puma levels were not altered in p $53+/-$ neurons (Fig. $6 B$ ), despite the $>50 \%$ reduction in p 53 mRNA levels (Fig. $6 \mathrm{~A}$ ), indicating that the $30 \%$ suppression of p53 expression by synaptic activity would not be sufficient to alter Puma levels. Analysis of p53 - /- neurons revealed that levels of Puma were
$33 \%$ lower than in p53 $+/+$ neurons, consistent with a role for p53 in Puma transcription (Fig. 6B). However, levels of Puma in unstimulated $\mathrm{p} 53-/-$ neurons were still significantly higher than in $\mathrm{BiC} / 4$-AP-stimulated wild-type neurons (Fig. 6B). Furthermore, $\mathrm{BiC} / 4-\mathrm{AP}$ stimulation still suppressed Puma expression in p53 -/neurons (Fig. $6 \mathrm{~B}$ ). The percentage reduction of Puma expression by $\mathrm{BiC} / 4-\mathrm{AP}$ stimulation in $\mathrm{p} 53+/+$ and $\mathrm{p} 53-/-$ neurons was unchanged ( $59 \pm 6 \%$ and $54 \pm 6 \%$, respectively). In addition, MK801 treatment resulted in a significant increase in Puma expression in p53-/- neurons (Fig. 6B). These data are consistent with 553 suppression not having a significant role in mediating the synaptic NMDAR-dependent Puma suppression (Lau and Bading, 2009). Moreover, p53 suppression is not involved in Apaf1 or Casp9 regulation since p53 deficiency had no effect on basal or activity-suppressed levels of Apaf1 or Casp9 (Fig. 6C). Acute knockdown of $\mathrm{p} 53$ has been shown to reduce Apaf1 expression in hippocampal neurons (Lau and Bading, 2009), so we looked more carefully at this promoter. We analyzed the activitydependent suppression of the Apaf1 promoter both with and without its two p53 binding sites, using luciferase reporters previously generated (Moroni et al., 2001). We observed a similar 
amount of activity-dependent suppression of the Apaf1 promoter in the presence or absence of its p53 sites, further suggesting that activity-dependent reduction of Apaf1 is not mediated by p53 in cortical neurons (supplemental Fig. S13, available at www.jneurosci.org as supplemental material).

We next analyzed the vulnerability of p53 $+/-$ and $-/-$ neurons to staurosporineinduced apoptosis. We found that staurosporine-induced apoptosis was slightly lower in p53-/- neurons, but unchanged in p53 $+/-$ neurons (Fig. $6 D$ ). BiC/4-APinduced synaptic activity still resulted in strong protection in $\mathrm{p} 53+/-$ and $-/-$ neurons, and MK-801 still increased levels of apoptosis (Fig. 6D). In our trophic deprivation model, the reduction in levels of death in p53-/- neurons was not statistically significant. Moreover, BiC/4-APinduced synaptic activity still resulted in strong protection in $\mathrm{p} 53+/-$ and $-/-$ neurons, and MK-801 still increased levels of apoptosis (Fig. 6E). We conclude that the activity-dependent protective pathways described here in cortical neurons are not dependent on p53 suppression. Any protective effect arising from $\mathrm{p} 53$ suppression will cooperate with the mechanisms described here to strongly suppress apoptosis.

\section{Discussion}

We have shown that key components of the neuronal intrinsic apoptosis pathway are subject to activity-dependent transcriptional shut-off, mediated largely by synaptic NMDAR activity. The result of these gene expression changes is to restrict the capacity of neurons to undergo apoptosis in response to a diverse array of stimuli.

\section{Synaptic NMDAR activity upregulates protective genes and downregulates pro-death genes}

In contrast to the adverse effects of excessive NMDAR activity, physiological levels of synaptic NMDAR activity are essential for neuronal survival, since activity blockade was shown to have deleterious effects. Blockade of NMDAR activity in vivo caused a decrease in the number of healthy cells, increased density of pyknotic cells, and severe deterioration of the dentate gyrus morphology in first week postnatal rat pups (Gould et al., 1994). Elimination of NMDA receptor activity in vivo causes widespread apoptosis and enhances trauma-induced injury in developing neurons (Gould et al., 1994; Ikonomidou et al., 1999; Pohl et al., 1999; Monti and Contestabile, 2000; Adams et al., 2004; Papadia et al., 2008). In the adult CNS, NMDAR blockade exacerbates neuronal loss when applied after traumatic brain injury and during ongoing neurodegeneration (Ikonomidou et al., 2000), and prevents the survival of newborn neurons in the adult dentate gyrus (Tashiro et al., 2006). NMDAR signaling to
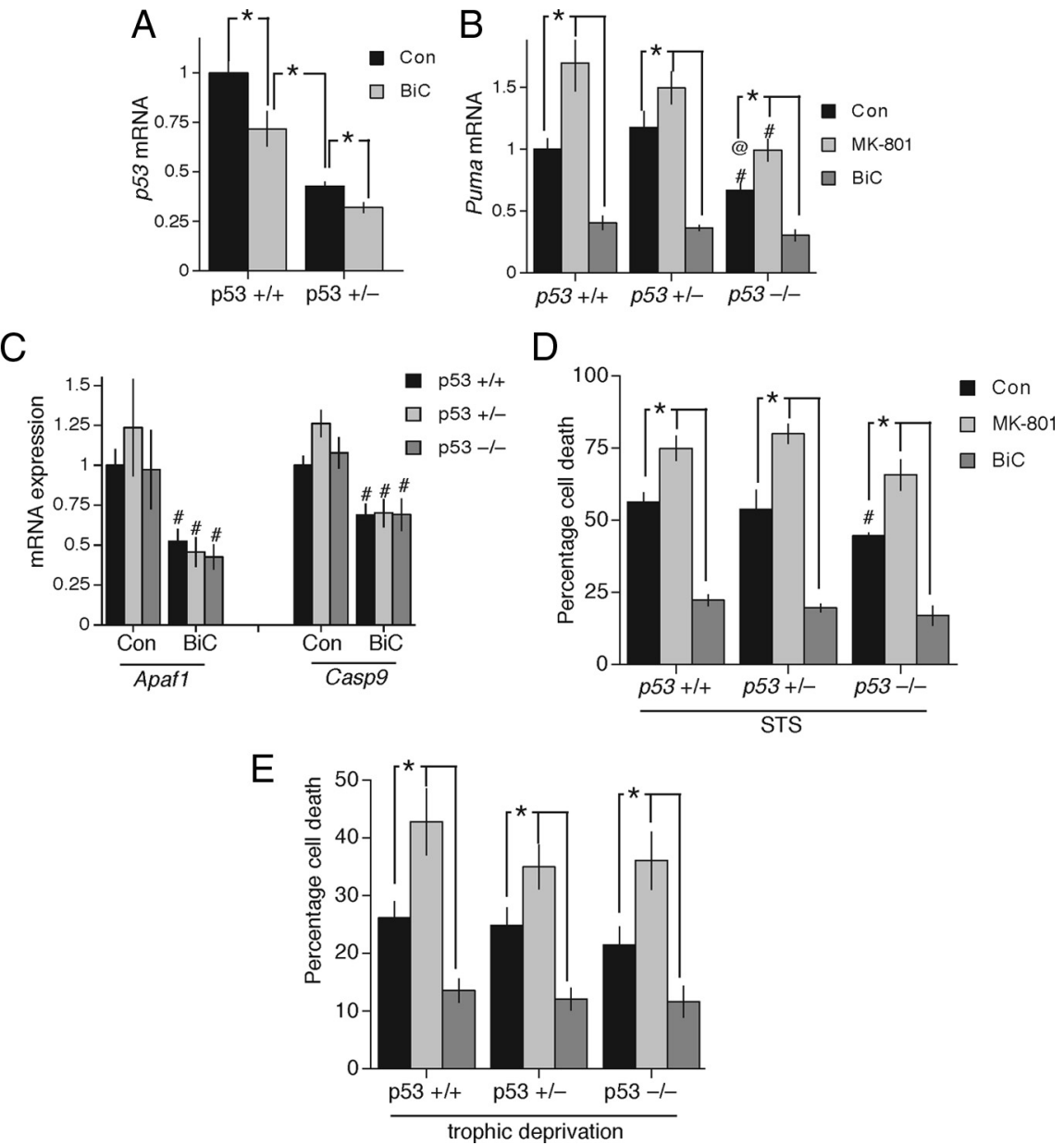

Figure 6. Neuroprotection due to activity-dependent suppression of Puma, Apaf-1, and Procaspase- 9 expression is not via p53 inhibition. $A, Q R T-P C R$ analysis of $p 53$ expression in $p 53+/+$ and $+/-$ neurons that were stimulated as indicated for $4 \mathrm{~h} .{ }^{*} p<0.05(n=6$ MK-801 treatment was for $24 \mathrm{~h}$. BiC/4-AP treatment was for $4 \mathrm{~h}$. ${ }^{*} p<0.05(n=6+/+, n=4+/-, n=4-/-)$ indicates Cosp 9 expression in $\mathrm{p} 53+/+,+/-$, and $-/-$ neurons stimulated where indicated with $\mathrm{BiC} / 4-\mathrm{AP}$ for $4 \mathrm{~h}$. $\# p<0.05$ compared to 作 induced apoptosis is not occluded by $\mathrm{p} 53$ deficiency. $\mathrm{p} 53+/+,+/-$, and $-/-$ neurons were stimulated as indicated for $72 \mathrm{~h}$ in trophically deprived medium, after which cell death was assessed. * $p<0.05(n=6+/+, n=4+/-, n=4-/-)$ indicates stimulus-dependent differences $(n=4)$. ${ }^{\#} p<0.05$ indicates differences due to genotype (i.e., compared to $+/+$ neurons treated in the same way). There are no such differences.

survival has been recapitulated in vitro in neuronal cultures (Hardingham, 2006; Hetman and Kharebava, 2006), allowing the underlying signaling events to be investigated. While pro-survival signaling from the NMDA receptor can involve posttranslational modifications of existing proteins, it is clear that changes in gene expression play a major role.

The negative coupling of several key proapoptotic genes to synaptic NMDAR activity, Puma, Apaf1, Casp9, Casp3, and Trp53 [this study and Lau and Bading (2009)], helps to explain how synaptic NMDAR activity can prevent apoptosis largely independent of the type of insult used. Unpublished microarray data from our laboratory indicate that the influence of synaptic NMDAR activity on core components of the intrinsic apoptosis pathway is restricted to the genes studied in this manuscript. Of 
the caspases, only Casp 9 and Casp3 are altered by $\mathrm{BiC} / 4-\mathrm{AP}$ treatment (and in a NMDAR-dependent manner). Furthermore, we find little evidence that anti-apoptotic members of the $\mathrm{Bcl} 2 \mathrm{fam}$ ily are globally upregulated: within this group, no member is induced (using 1.5-fold as the threshold), nor are any IAP genes upregulated. Of all the proapoptotic members of the Bcl 2 family (including the Bax subfamily), Puma is the only gene suppressed by $\mathrm{BiC} / 4-\mathrm{AP}$ treatment. However, we observed an upregulation of $\mathrm{Bcl} 2 \mathrm{l11}$ (Bim) and Hrk expression by MK-801 treatment, confirmed by qPCR (data not shown). Thus, while regulation of Bim or Hrk is not associated with neuroprotection evoked by strong synaptic NMDAR activity evoked by BiC/4-AP, induction of these genes may contribute in part to apoptosis induced by blocking all NMDAR activity by MK-801. However, given that MK801-induced death is abolished in Puma-deficient neurons (Fig. $3 C$ ), this shows that Bim and Hrk induction are not sufficient to trigger apoptosis in the absence of Puma. This is consistent with studies that suggest a stronger role for Puma in neuronal apoptosis than Hrk or Bim, potentially due to it being a stronger direct activator of Bax (Steckley et al., 2007; Ghosh et al., 2009).

The pro-survival effects of shutting off key components of the intrinsic apoptotic machinery is accompanied by further protection mediated by the nuclear $\mathrm{Ca}^{2+}$-dependent upregulation of pro-survival gene expression, mediated by CREB and potentially other factors (Hardingham et al., 2001; Papadia et al., 2005; Zhang et al., 2009a). Such genes include Bdnf (Hardingham et al., 2002; Soriano et al., 2006), Btg2, a potentially anti-apoptotic CREB target gene, and $B c l 6$, a transcriptional repressor implicated in suppression of p53 (Zhang et al., 2007) as well as several other nuclear $\mathrm{Ca}^{2+}$-regulated neuroprotective genes very recently identified (Zhang et al., 2009a). The anti-apoptotic effects of the above-mentioned changes in gene expression are augmented by others in the context of promoting resistance to one apoptotic insult of particular relevance to neurodegeneration: oxidative stress. Synaptic NMDAR activity induces strong upregulation of intrinsic antioxidant defenses involving increased capacity of both the thioredoxin/peroxiredoxin system (Papadia et al., 2008) and the glutathione system (G. E. Hardingham, unpublished observations). As well as detoxifying harmful radicals and ROS, the reducing capacity of these systems may directly influence the intrinsic apoptosis cascade, since reduction of cytochrome $c$ (to the $\mathrm{Fe}^{2+}$ form) renders it unable to trigger apoptosome formation and caspase activation (Brown and Borutaite, 2008).

The changes in antioxidant defenses triggered by synaptic activity are mediated by a coordinated program of gene expression. For example, synaptic activity induces expression of sulfiredoxin, the enzyme responsible for reduction of hyperoxidized peroxiredoxins, as well as suppressing expression of the thioredoxin inhibitor Txnip (Papadia et al., 2008). The latter represents the first example of a pro-death gene whose expression is suppressed by synaptic activity. We found Txnip to be subject to transcriptional regulation by the FOXO (forkhead box O) subfamily of forkhead transcription factors, inactivated when induction of the PI3K (phosphoinositide-3-kinase)-Akt kinase cascade results in export of FOXOs from the nucleus to the cytoplasm.

Despite the phosphoinositide-3-kinase (PI3K)-dependent suppression of FOXO activity and expression by synaptic activity (AlMubarak et al., 2009), and reported involvement of FOXOs in the expression of Puma, PI3K inhibition did not interfere with suppression of Puma, nor indeed Apaf1, Casp9, or Casp3 (data not shown), raising the question as to the mechanism involved. Puma and Apaf1 are also reported p53 targets, but suppression of these genes was observed in p53-deficient neurons, ruling out p53 inhibition as a dominant mechanism in cortical neurons (Fig. 6). Of note, Apaf-1 expression is sensitive to reduction in p53 levels in hippocampal neurons (Lau and Bading, 2009), suggesting that basal p53 activity may be higher in hippocampal neurons than cortical neurons.

We considered whether enhanced histone acetylation may underlie suppression of these proapoptotic genes, since activitymediated changes in promoter acetylation status do occur (Soriano et al., 2009). We found that inhibition of Class I and II histone deacetylases by treatment with trichostatin A (TSA) did not elevate basal expression of Puma or Casp9, nor did it block their activity-dependent suppression (data not shown). In the case of Apaf1, TSA treatment resulted in upregulation of its expression (data not shown), as has been shown in sympathetic neurons (Wright et al., 2007). However, induction of synaptic activity still resulted in its transcriptional suppression (data not shown). Thus, changes in histone acetylation are unlikely to be involved in activity-dependent suppression of these proapoptotic genes.

\section{Apoptotic biochemical cascades in neurodegenerative disease} Although the issue remains controversial, there is growing evidence that the death of neurons in many neurodegenerative diseases can occur by apoptosis or related mechanisms that involve apoptotic biochemical cascades (Mattson, 2006; Ribe et al., 2008; Rohn and Head, 2009). Increased levels of activated caspase- 9 have been observed in Alzheimer's disease ( $\mathrm{AD}$, hippocampus), Huntington's disease (HD, striatum), Parkinson's disease (PD, substantia nigra), and amyotrophic lateral sclerosis (ALS, spinal cord) (Kiechle et al., 2002; Inoue et al., 2003; Tatton et al., 2003; Ribe et al., 2008; Rohn and Head, 2009), implicating the intrinsic apoptosis pathway in disease progression. Furthermore, apoptosis and caspase activation are implicated in multiple in vitro and animal models of neurodegeneration (Ferraro et al., 2003; Mattson, 2006; Ribe et al., 2008). Inhibition of caspases has been reported to be protective in models of ALS, HD, and PD (Friedlander, 2003; Rohn and Head, 2009).

In $\mathrm{AD}$, there is good evidence that caspases have a proximal role in disease progression and not just in terminal neurodegeneration (Rohn and Head, 2009). Increased expression of procaspase- 9 has been observed in AD brains, as well as other caspases (Cotman and Anderson, 1995) and activation of caspases is also observed even in subjects with mild AD (Gastard et al., 2003; Rohn and Head, 2009). Amyloid $\beta$ (A $\beta$ )-induced oxidative stress triggers caspase activation through the intrinsic mitochondrial pathway. Executioner caspases, particularly caspase-3, then cleave APP, which may facilitate the production of $A \beta$ (Gervais et al., 1999), potentially resulting in a feedforward cycle of $\mathrm{A} \beta$ production and caspase- 3 activation. Tau is also a substrate for Caspase-3, and cleavage of tau may promote aggregation and paired helical filament formation (Gamblin et al., 2003; Rohn and Head, 2009). Caspase activation is also implicated in localized neurite and nerve terminal degeneration (Marx, 2001), which may occur well in advance of any cell death. Recently the benefits of inhibiting the intrinsic apoptotic biochemical cascade were demonstrated in the triple transgenic AD mouse model (Oddo et al., 2003; Rohn et al., 2008). Overexpression of the antiapoptotic Bcl-2 gene blocked activation of caspase- 9 and caspase-3. Processing of tau and APP was suppressed, there were reduced numbers of NFTs and deposits of A $\beta$, and memory performance was improved (Rohn et al., 2008).

Upstream of apoptosome formation, regulation of bcl-2 family members is also implicated in neurodegenerative disease. Upregulation of the proapoptotic bcl-2 family member Bax is observed in 
several neurodegenerative diseases (Tatton et al., 2003; Mattson, 2006). Dysregulation of Puma may also be involved in neurodegeneration. Puma is an important mediator of motoneuron death in a mouse ALS (SOD1) model (Kieran et al., 2007). Upregulation of Puma is associated with an animal model of Parkinson's disease (Karunakaran et al., 2008), and is required for cell death in a cellular model of PD (Biswas et al., 2005). Induction of Puma expression also occurs in the striatum in a metabolic inhibition model of Huntington's disease (Zhang et al., 2009b), and upregulation of Puma and other $\mathrm{BH} 3$-only proteins may also contribute to delayed neuronal loss following ischemia (Webster et al., 2006; Niizuma et al., 2009).

Our findings that synaptic activity can strongly suppress expression of genes encoding Puma, procaspase-9, its upstream activator Apaf-1, and downstream effector caspase- 3 suggest that active neurons may be more resistant to certain aspects of caspase-associated disease progression. Conversely, deprivation of normal neuronal activity as part of the disease process (such as through nerve terminal degeneration) may result in the de-repression of these genes and subsequently exacerbate disease progression. As well as suppressing the apoptotic machinery, neuronal activity also boosts neuronal antioxidant defenses via a coordinated program of gene expression changes (Papadia et al., 2008) and upregulates nuclear $\mathrm{Ca}^{2+}$ dependent pro-survival genes (Papadia et al., 2005; Zhang et al., 2009a). One could envisage that depleted antioxidant defenses, coupled with upregulated proapoptotic genes and insufficient nuclear $\mathrm{Ca}^{2+}$ signaling could all contribute to loss of neuronal function and/or viability when neurons are deprived of activity.

\section{References}

Adams SM, de Rivero Vaccari JC, Corriveau RA (2004) Pronounced cell death in the absence of NMDA receptors in the developing somatosensory thalamus. J Neurosci 24:9441-9450.

Akhtar RS, Geng Y, Klocke BJ, Latham CB, Villunger A, Michalak EM, Strasser A, Carroll SL, Roth KA (2006) BH3-only proapoptotic Bcl-2 family members Noxa and Puma mediate neural precursor cell death. J Neurosci 26:7257-7264.

Al-Mubarak B, Soriano FX, Hardingham GE (2009) Synaptic NMDAR activity suppresses FOXO1 expression via a cis-acting FOXO binding site: FOXO1 is a FOXO target gene. Channels (Austin) 3:233-238.

Bading H, Ginty DD, Greenberg ME (1993) Regulation of gene expression in hippocampal neurons by distinct calcium signaling pathways. Science 260:181-186.

Benn SC, Woolf CJ (2004) Adult neuron survival strategies—slamming on the brakes. Nat Rev Neurosci 5:686-700.

Biswas SC, Ryu E, Park C, Malagelada C, Greene LA (2005) Puma and p53 play required roles in death evoked in a cellular model of Parkinson disease. Neurochem Res 30:839-845.

Brown GC, Borutaite V (2008) Regulation of apoptosis by the redox state of cytochrome c. Biochim Biophys Acta 1777:877-881.

Buss RR, Sun W, Oppenheim RW (2006) Adaptive roles of programmed cell death during nervous system development. Annu Rev Neurosci 29:1-35.

Catsicas M, Péquignot Y, Clarke PGH (1992) Rapid onset of neuronal death induced by blockade of either axoplasmic transport or action potentials in afferent fibers during brain development. J Neurosci 12:4642-4650.

Chen LQ, Wei JS, Lei ZN, Zhang LM, Liu Y, Sun FY (2005) Induction of Bcl-2 and Bax was related to hyperphosphorylation of tau and neuronal death induced by okadaic acid in rat brain. Anat Rec A Discov Mol Cell Evol Biol 287:1236-1245.

Cotman CW, Anderson AJ (1995) A potential role for apoptosis in neurodegeneration and Alzheimer's disease. Mol Neurobiol 10:19-45.

Culmsee C, Landshamer S (2006) Molecular insights into mechanisms of the cell death program: role in the progression of neurodegenerative disorders. Curr Alzheimer Res 3:269-283.

Ferraro E, Corvaro M, Cecconi F (2003) Physiological and pathological roles of Apaf1 and the apoptosome. J Cell Mol Med 7:21-34.

Friedlander RM (2003) Apoptosis and caspases in neurodegenerative diseases. N Engl J Med 348:1365-1375.

Fujimura S, Suzumiya J, Yamada Y, Kuroki M, Ono J (2003) Downregula- tion of Bcl-xL and activation of caspases during retinoic acid-induced apoptosis in an adult T-cell leukemia cell line. Hematol J 4:328-335.

Gamblin TC, Chen F, Zambrano A, Abraha A, Lagalwar S, Guillozet AL, Lu M, Fu Y, Garcia-Sierra F, LaPointe N, Miller R, Berry RW, Binder LI, Cryns VL (2003) Caspase cleavage of tau: linking amyloid and neurofibrillary tangles in Alzheimer's disease. Proc Natl Acad Sci U S A 100:10032-10037.

Gastard MC, Troncoso JC, Koliatsos VE (2003) Caspase activation in the limbic cortex of subjects with early Alzheimer's disease. Ann Neurol 54:393-398.

Gervais FG, Xu D, Robertson GS, Vaillancourt JP, Zhu Y, Huang J, LeBlanc A, Smith D, Rigby M, Shearman MS, Clarke EE, Zheng H, Van Der Ploeg LH, Ruffolo SC, Thornberry NA, Xanthoudakis S, Zamboni RJ, Roy S, Nicholson DW (1999) Involvement of caspases in proteolytic cleavage of Alzheimer's amyloid-beta precursor protein and amyloidogenic A beta peptide formation. Cell 97:395-406.

Ghosh AP, Walls KC, Klocke BJ, Toms R, Strasser A, Roth KA (2009) The proapoptotic BH3-only, Bcl-2 family member, Puma is critical for acute ethanol-induced neuronal apoptosis. J Neuropathol Exp Neurol 68:747-756.

Gould E, Cameron HA, McEwen BS (1994) Blockade of NMDA receptors increases cell death and birth in the developing rat dentate gyrus. J Comp Neurol 340:551-565.

Halliwell B (2006) Oxidative stress and neurodegeneration: where are we now? J Neurochem 97:1634-1658.

Hardingham GE (2006) Pro-survival signalling from the NMDA receptor. Biochem Soc Trans 34:936-938.

Hardingham GE (2009) Coupling of the NMDA receptor to neuroprotective and neurodestructive events. Biochem Soc Trans 37:1147-1160.

Hardingham GE, Arnold FJ, Bading H (2001) Nuclear calcium signaling controls CREB-mediated gene expression triggered by synaptic activity. Nat Neurosci 4:261-267.

Hardingham GE, Fukunaga Y, Bading H (2002) Extrasynaptic NMDARs oppose synaptic NMDARs by triggering CREB shut-off and cell death pathways. Nat Neurosci 5:405-414.

Hetman M, Kharebava G (2006) Survival signaling pathways activated by NMDA receptors. Curr Top Med Chem 6:787-799.

Horváth ZC, Czopf J, Buzsáki G (1997) MK-801-induced neuronal damage in rats. Brain Res 753:181-195.

Ikonomidou C, Bosch F, Miksa M, Bittigau P, Vöckler J, Dikranian K, Tenkova TI, Stefovska V, Turski L, Olney JW (1999) Blockade of NMDA receptors and apoptotic neurodegeneration in the developing brain. Science 283:70-74.

Ikonomidou C, Stefovska V, Turski L (2000) Neuronal death enhanced by $\mathrm{N}$-methyl-D-aspartate antagonists. Proc Natl Acad Sci U S A 97:12885-12890.

Inoue $\mathrm{H}$, Tsukita $\mathrm{K}$, Iwasato $\mathrm{T}$, Suzuki $\mathrm{Y}$, Tomioka $\mathrm{M}$, Tateno $\mathrm{M}$, Nagao $\mathrm{M}$, Kawata A, Saido TC, Miura M, Misawa H, Itohara S, Takahashi R (2003) The crucial role of caspase- 9 in the disease progression of a transgenic ALS mouse model. EMBO J 22:6665-6674.

Jayaraj R, Gupta N, Rao PV (2009) Multiple signal transduction pathways in okadaic acid induced apoptosis in HeLa cells. Toxicology 256:118-127.

Karunakaran S, Saeed U, Mishra M, Valli RK, Joshi SD, Meka DP, Seth P, Ravindranath V (2008) Selective activation of p38 mitogen-activated protein kinase in dopaminergic neurons of substantia nigra leads to nuclear translocation of p53 in 1-methyl-4-phenyl-1,2,3,6-tetrahydropyridine-treated mice. J Neurosci 28:12500-12509.

Kiechle T, Dedeoglu A, Kubilus J, Kowall NW, Beal MF, Friedlander RM, Hersch SM, Ferrante RJ (2002) Cytochrome C and caspase-9 expression in Huntington's disease. Neuromolecular Med 1:183-195.

Kieran D, Woods I, Villunger A, Strasser A, Prehn JH (2007) Deletion of the $\mathrm{BH} 3$-only protein puma protects motoneurons from ER stress-induced apoptosis and delays motoneuron loss in ALS mice. Proc Natl Acad Sci U S A 104:20606-20611.

Lau D, Bading H (2009) Synaptic activity-mediated suppression of p53 and induction of nuclear calcium-regulated neuroprotective genes promote survival through inhibition of mitochondrial permeability transition. J Neurosci 29:4420-4429.

Linden R (1994) The survival of developing neurons: a review of afferent control. Neuroscience 58:671-682.

Marx J (2001) Neuroscience. New leads on the 'how' of Alzheimer's. Science 293:2192-2194.

Mattson MP (2006) Neuronal life-and-death signaling, apoptosis, and neurodegenerative disorders. Antioxid Redox Signal 8:1997-2006. 
Mckenzie GJ, Stevenson P, Ward G, Papadia S, Bading H, Chawla S, Privalsky M, Hardingham GE (2005) Nuclear Ca2+ and CaM kinase IV specify hormonal- and Notch-responsiveness. J Neurochem 93:171-185.

Meier P, Vousden KH (2007) Lucifer's labyrinth—ten years of path finding in cell death. Mol Cell 28:746-754.

Mennerick S, Zorumski CF (2000) Neural activity and survival in the developing nervous system. Mol Neurobiol 22:41-54.

Miñambres E, Ballesteros MA, Mayorga M, Marin MJ, Muñoz P, Figols J, LópezHoyos M (2008) Cerebral apoptosis in severe traumatic brain injury patients: an in vitro, in vivo, and postmortem study. J Neurotrauma 25:581-591.

Monti B, Contestabile A (2000) Blockade of the NMDA receptor increases developmental apoptotic elimination of granule neurons and activates caspases in the rat cerebellum. Eur J Neurosci 12:3117-3123.

Moroni MC, Hickman ES, Lazzerini Denchi E, Caprara G, Colli E, Cecconi F, Müller H, Helin K (2001) Apaf-1 is a transcriptional target for E2F and p53. Nat Cell Biol 3:552-558.

Mouratidis PX, Dalgleish AG, Colston KW (2006) Investigation of the mechanisms by which EB1089 abrogates apoptosis induced by 9-cis retinoic acid in pancreatic cancer cells. Pancreas 32:93-100.

Niizuma K, Endo H, Nito C, Myer DJ, Chan PH (2009) Potential role of PUMA in delayed death of hippocampal CA1 neurons after transient global cerebral ischemia. Stroke 40:618-625.

Nör JE, Hu Y, Song W, Spencer DM, Núñez G (2002) Ablation of microvessels in vivo upon dimerization of iCaspase-9. Gene Ther 9:444-451.

Oddo S, Caccamo A, Shepherd JD, Murphy MP, Golde TE, Kayed R, Metherate R, Mattson MP, Akbari Y, LaFerla FM (2003) Triple-transgenic model of Alzheimer's disease with plaques and tangles: intracellular Abeta and synaptic dysfunction. Neuron 39:409-421.

Olney JW, Labruyere J, Price MT (1989) Pathological changes induced in cerebrocortical neurons by phencyclidine and related drugs. Science 244:1360-1362.

Olney JW, Wozniak DF, Jevtovic-Todorovic V, Farber NB, Bittigau P, Ikonomidou C (2002) Drug-induced apoptotic neurodegeneration in the developing brain. Brain Pathology 12:488-498.

Papadia S, Stevenson P, Hardingham NR, Bading H, Hardingham GE (2005) Nuclear $\mathrm{Ca}^{2+}$ and the cAMP response element-binding protein family mediate a late phase of activity-dependent neuroprotection. J Neurosci 25:4279-4287.

Papadia S, Soriano FX, Léveillé F, Martel MA, Dakin KA, Hansen HH, Kaindl A, Sifringer M, Fowler J, Stefovska V, McKenzie G, Craigon M, Corriveau R, Ghazal P, Horsburgh K, Yankner BA, Wyllie DJ, Ikonomidou C, Hardingham GE (2008) Synaptic NMDA receptor activity boosts intrinsic antioxidant defenses. Nat Neurosci 11:476-487.

Pohl D, Bittigau P, Ishimaru MJ, Stadthaus D, Hübner C, Olney JW, Turski L, Ikonomidou C (1999) N-Methyl-D-aspartate antagonists and apoptotic cell death triggered by head trauma in developing rat brain. Proc Natl Acad Sci U S A 96:2508-2513.

Potts PR, Singh S, Knezek M, Thompson CB, Deshmukh M (2003) Critical function of endogenous XIAP in regulating caspase activation during sympathetic neuronal apoptosis. J Cell Biol 163:789-799.

Ray SK (2006) Currently evaluated calpain and caspase inhibitors for neuroprotection in experimental brain ischemia. Curr Med Chem 13:3425-3440.

Ribe EM, Serrano-Saiz E, Akpan N, Troy CM (2008) Mechanisms of neuronal death in disease: defining the models and the players. Biochem J 415:165-182.

Riedl SJ, Salvesen GS (2007) The apoptosome: signalling platform of cell death. Nat Rev Mol Cell Biol 8:405-413.

Rohn TT, Head E (2009) Caspases as therapeutic targets in Alzheimer's disease: is it time to "cut" to the chase? Int J Clin Exp Pathol 2:108-118.

Rohn TT, Vyas V, Hernandez-Estrada T, Nichol KE, Christie LA, Head E (2008) Lack of pathology in a triple transgenic mouse model of Alzheimer's disease after overexpression of the anti-apoptotic protein Bcl-2. J Neurosci 28:3051-3059.

Roy SS, Madesh M, Davies E, Antonsson B, Danial N, Hajnóczky G (2009) Bad targets the permeability transition pore independent of Bax or Bak to switch between Ca2+-dependent cell survival and death. Mol Cell 33:377-388.

Soriano FX, Papadia S, Hofmann F, Hardingham NR, Bading H, Hardingham GE (2006) Preconditioning doses of NMDA promote neuroprotection by enhancing neuronal excitability. J Neurosci 26:4509-4518.

Soriano FX, Léveillé F, Papadia S, Higgins LG, Varley J, Baxter P, Hayes JD,
Hardingham GE (2008) Induction of sulfiredoxin expression and reduction of peroxiredoxin hyperoxidation by the neuroprotective Nrf2 activator 3H-1,2-dithiole-3-thione. J Neurochem 107:533-543.

Soriano FX, Papadia S, Bell KF, Hardingham GE (2009) Role of histone acetylation in the activity-dependent regulation of sulfiredoxin and sestrin 2. Epigenetics 4:152-158.

Steckley D, Karajgikar M, Dale LB, Fuerth B, Swan P, Drummond-Main C, Poulter MO, Ferguson SS, Strasser A, Cregan SP (2007) Puma is a dominant regulator of oxidative stress induced Bax activation and neuronal apoptosis. J Neurosci 27:12989-12999.

Tashiro A, Sandler VM, Toni N, Zhao C, Gage FH (2006) NMDA-receptormediated, cell-specific integration of new neurons in adult dentate gyrus. Nature 442:929-933.

Tatton WG, Chalmers-Redman R, Brown D, Tatton N (2003) Apoptosis in Parkinson's disease: signals for neuronal degradation. Ann Neurol 53 Suppl 3:S61-S70; discussion S70-S72.

Tsujimoto K, Ono T, Sato M, Nishida T, Oguma T, Tadakuma T (2005) Regulation of the expression of caspase- 9 by the transcription factor activator protein-4 in glucocorticoid-induced apoptosis. J Biol Chem 280:27638-27644.

Uo T, Kinoshita Y, Morrison RS (2007) Apoptotic actions of p53 require transcriptional activation of PUMA and do not involve a direct mitochondrial/cytoplasmic site of action in postnatal cortical neurons. J Neurosci 27:12198-12210.

Villunger A, Michalak EM, Coultas L, Müllauer F, Böck G, Ausserlechner MJ, Adams JM, Strasser A (2003) p53- and drug-induced apoptotic responses mediated by BH3-only proteins puma and noxa. Science 302:1036-1038.

Viswanath V, Wu Y, Boonplueang R, Chen S, Stevenson FF, Yantiri F, Yang L, Beal MF, Andersen JK (2001) Caspase-9 activation results in downstream caspase- 8 activation and bid cleavage in 1-methyl-4-phenyl-1,2,3,6tetrahydropyridine-induced Parkinson's disease. J Neurosci 21:9519-9528.

Webster KA, Graham RM, Thompson JW, Spiga MG, Frazier DP, Wilson A, Bishopric NH (2006) Redox stress and the contributions of BH3-only proteins to infarction. Antioxid Redox Signal 8:1667-1676.

Wong HK, Fricker M, Wyttenbach A, Villunger A, Michalak EM, Strasser A, Tolkovsky AM (2005) Mutually exclusive subsets of BH3-only proteins are activated by the p53 and c-Jun $\mathrm{N}$-terminal kinase/c-Jun signaling pathways during cortical neuron apoptosis induced by arsenite. Mol Cell Biol 25:8732-8747.

Wozniak DF, Dikranian K, Ishimaru MJ, Nardi A, Corso TD, Tenkova T, Olney JW, Fix AS (1998) Disseminated corticolimbic neuronal degeneration induced in rat brain by MK-801: potential relevance to Alzheimer's disease. Neurobiol Dis 5:305-322.

Wright KM, Linhoff MW, Potts PR, Deshmukh M (2004) Decreased apoptosome activity with neuronal differentiation sets the threshold for strict IAP regulation of apoptosis. J Cell Biol 167:303-313.

Wright KM, Smith MI, Farrag L, Deshmukh M (2007) Chromatin modification of Apaf-1 restricts the apoptotic pathway in mature neurons. J Cell Biol 179:825-832.

Wu WS, Heinrichs S, Xu D, Garrison SP, Zambetti GP, Adams JM, Look AT (2005) Slug antagonizes p53-mediated apoptosis of hematopoietic progenitors by repressing puma. Cell 123:641-653.

Wyttenbach A, Tolkovsky AM (2006) The BH3-only protein Puma is both necessary and sufficient for neuronal apoptosis induced by DNA damage in sympathetic neurons. J Neurochem 96:1213-1226.

Youle RJ, Strasser A (2008) The BCL-2 protein family: opposing activities that mediate cell death. Nat Rev Mol Cell Biol 9:47-59.

Yu J, Zhang L, Hwang PM, Kinzler KW, Vogelstein B (2001) PUMA induces the rapid apoptosis of colorectal cancer cells. Mol Cell 7:673-682.

Zhang SJ, Steijaert MN, Lau D, Schütz G, Delucinge-Vivier C, Descombes P, Bading H (2007) Decoding NMDA receptor signaling: identification of genomic programs specifying neuronal survival and death. Neuron 53: 549-562.

Zhang SJ, Zou M, Lu L, Lau D, Ditzel DA, Delucinge-Vivier C, Aso Y, Descombes P, Bading H (2009a) Nuclear calcium signaling controls expression of a large gene pool: identification of a gene program for acquired neuroprotection induced by synaptic activity. PLoS Genet 5:e1000604.

Zhang XD, Wang Y, Wang Y, Zhang X, Han R, Wu JC, Liang ZQ, Gu ZL, Han F, Fukunaga K, Qin ZH (2009b) p53 mediates mitochondria dysfunctiontriggered autophagy activation and cell death in rat striatum. Autophagy 5:339-350. 